\title{
Emerging Functions of Regulatory T Cells in Tissue Homeostasis
}

\author{
Amit Sharma ${ }^{1,2}$ and Dipayan Rudra ${ }^{1,2 *}$ \\ ${ }^{1}$ Academy of Immunology and Microbiology, Institute for Basic Science (IBS), Pohang, South Korea, ${ }^{2}$ Division of Integrative \\ Biosciences and Biotechnology, Pohang University of Science and Technology (POSTECH), Pohang, South Korea
}

OPEN ACCESS

Edited by:

Amit Awasthi,

Translational Health Science and

Technology Institute, India

Reviewed by:

Koji Yasutomo,

Tokushima University, Japan

Zhaocai Zhou,

Institute of Biochemistry and Cell

Biology, Shanghai Institutes for

Biological Sciences (CAS), China

*Correspondence:

Dipayan Rudra

rudrad@ibs.re.kr

Specialty section:

This article was submitted

to T Cell Biology,

a section of the journal

Frontiers in Immunology

Received: 28 February 2018

Accepted: 10 April 2018

Published: 25 April 2018

Citation:

Sharma A and Rudra D (2018) Emerging Functions of Regulatory

$T$ Cells in Tissue Homeostasis.

Front. Immunol. 9:883.

doi: 10.3389/fimmu.2018.00883
$\mathrm{CD}^{+}{ }^{+} \mathrm{Foxp}^{+}$regulatory T-cells (Tregs) are a unique subset of helper T-cells, which regulate immune response and establish peripheral tolerance. Tregs not only maintain the tone and tenor of an immune response by dominant tolerance but, in recent years, have also been identified as key players in resolving tissue inflammation and as mediators of tissue healing. Apart from being diverse in their origin (thymic and peripheral) and location (lymphoid and tissue resident), Tregs are also phenotypically heterogeneous as per the orientation of ongoing immune response. In this review, we discuss the recent advances in the field of Treg biology in general, and non-lymphoid and tissue-resident Tregs in particular. We elaborate upon well-known visceral adipose tissue, colon, skin, and tumor-infiltrating Tregs and newly identified tissue Treg populations as in lungs, skeletal muscle, placenta, and other tissues. Our attempt is to differentiate Tregs based on distinctive properties of their location, origin, ligand specificity, chemotaxis, and specific suppressive mechanisms. Despite ever expanding roles in maintaining systemic homeostasis, Tregs are employed by large varieties of tumors to dampen antitumor immunity. Thus, a comprehensive understanding of Treg biology in the context of inflammation can be instrumental in effectively managing tissue transplantation, autoimmunity, and antitumor immune responses.

Keywords: immune tolerance, autoimmunity, regulatory T cells, regulatory T-cells, Foxp3, tissue Treg, tumor Treg, regeneration

\section{INTRODUCTION}

Vertebrate immune and nervous system are two systems which are cognitive and under continuous interaction with the environment. This probably explains why both share common paradigms like recognition, learning or modulation, and memory. For long, immunology has been defined as a science of "self/non-self" discrimination (1). However, overtime, the immunological concept of "self" has evolved, where the very definition of an individual with defined anatomic borders, compatible balance between its parts, physiological autonomy, and ability to replicate as a unit is rapidly challenged by symbionts. Immune identity is now considered more fluid than restricted in strict borders (2). Hence, apart from generating a protective and offensive backdrop, the immune system must work to maintain an organismal identity by mediating dynamic exchange processes with the environment. This not only entails to generate robust defense against pathogens and toxins but also makes it rather paramount to suppress an overzealous immune response, curb autoimmune reactions, and maintain equilibrium toward commensals and food. Several mechanisms like clonal deletion, editing, anergy, ignorance, and immune deviation have evolved to safeguard against self-directed immunity (3). Specialized cells with immunosuppressive capabilities like 
tolerogenic dendritic cells (DCs) (4-6), regulatory B cells $(7,8)$, regulatory innate lymphoid cells $(9)$, type 1 regulatory (Tr1) T-cells (10), and Foxp $3^{+}$regulatory T-cells (Tregs) (11-13) have also evolved.

Regulatory T-cells are arguably the most versatile immunosuppressive cells and work like immunological sentinels across various tissues. Both in mice and men, loss of these cells essentially results in breakdown of tolerance and multi-organ autoimmunity. Since their discovery, biology of Tregs has been a most dynamic field of immunological research and as a result, Tregs, which were once considered as a homogenous immunosuppressive population, have been found to be highly adaptable and diversified cell type. Their heterogeneity is now appreciated in the context of origin, localization, differentiation, and mechanisms of immunosuppression. In the first part of this review, we will briefly discuss the events which put Tregs to the center stage of immune research, following which we will attempt to elaborate on the various layers of Treg heterogeneity especially pertaining to non-lymphoid and tissue-resident Tregs.

\section{CONCEPT OF "DOMINANT" TOLERANCE AND THE EMERGENCE OF REGULATORY T-CELL RESEARCH}

T-cell tolerance is pivotal for regulating adaptive immune responses as $\mathrm{T}$-cell help is essential for mounting an antibody response via B cells (14). T-cell tolerance for long, was studied in light of "recessive tolerance," wherein T-cells with high affinity TCRs toward self-antigens are clonally deleted (15), or undergo "receptor editing" in thymus $(16,17)$. The runaway cells which escape these central processes encounter anergy or activation induced cell death in the periphery $(15,18)$. However, studies on tolerance ushered into an "active" or "dominant" era with the seminal discovery of suppressive $\mathrm{CD} 4^{+} \mathrm{T}$-cells expressing high levels of high efficiency $\alpha$-chain receptor of IL2 (CD25) (19).

\section{The Outset of Treg Research}

Preliminary evidences of suppressive cells maintained in thymus started emerging when several investigators reported that neonatal thymectomy ( 3 day postnatal, $3 \mathrm{dTx}$ ) could induce various autoimmune diseases in suitable mouse strains (20-25). Even more astonishing was the fact that similarly induced disease processes in rats could be reversed by reconstitution with normal lymphoid cells (26). Several groups tried to identify specific markers to distinguish suppressive cells from pathogenic T-cells in the thymus. It was reported that T-cells depleted of $\mathrm{CD} 4^{+} \mathrm{CD} 5^{\text {hi }}$ cells induced autoimmune phenotype akin to $3 \mathrm{dTx}$ in BALB/c and $\mathrm{C} 3 \mathrm{H}$ mice (27). Two other groups demonstrated the capability of $\mathrm{CD}^{+} \mathrm{CD} 45 \mathrm{RB}^{\text {hi }} \mathrm{T}$-cells in inducing inflammatory bowel disease in BALB/c SCID mice $(28,29)$ and its resolution upon reconstitution with total T-cells. While these studies demonstrated that phenotypically distinct subsets of T-cells are capable of mounting discrete immune responses, specific identity of tolerance inducing counterparts remained elusive. Sakaguchi et al. in 1995 (19) discovered high surface expression of CD25 on about $8-10 \%$ of $\mathrm{CD}^{+}$T-cells, which were both $\mathrm{CD} 5^{\text {hi }}$ and $\mathrm{CD} 45 \mathrm{RB}^{\text {lo }}$ in concordance with previous studies. Asano et al. (30) demonstrated that $\mathrm{CD} 4{ }^{+} \mathrm{CD} 25^{+} \mathrm{T}$-cells appear around day 3 postnatal and increase up to the adult levels by day 10 . These authors were the first to propose the term "regulatory" for this subtype.

\section{Discovery of Foxp3}

While subsequent studies involving numerous experimental models of autoimmunity established its functional existence (31), the usage of CD25 as a marker for Tregs remained controversial for a number of years due to its upregulation in all activated T-cells. Furthermore, it seemed possible that a subset of the activated T-cells, by virtue of marked upregulation of the IL2 receptor $\alpha$ on their surface, restrained immune response simply by competing for IL2.

A mouse line dubbed "scurfy," with spontaneous autoimmunity (originally appeared as a spontaneous mutation at the Oak ridge national laboratory, USA under the Manhattan project), was immunologically characterized in 1991. Scurfy mice have an $\mathrm{X}$-linked recessive mutation which leads to scaly skin, lymphoproliferation, hypergammaglobulinemia, lymphadenomegaly, anemia, runting, and early death (32). Thymectomy reduced the severity of the disease but did not totally ameliorate it. However, crossing the strain with $n u / n u$ mice totally prevented the disease, suggesting thymic origin of disease causing cells. Several other studies revealed scurfy to be mainly a T-cell dependent disorder (33-35) much similar to Cytotoxic T-Lymphocyte Associated Protein 4 (CTLA4) (36) and Transforming growth factor $\beta 1$ (TGF $\beta 1$ ) deficient animals (37). These similarities instigated investigations to identify the gene responsible for scurfy phenotype. In 2001, Brunkow et al. (38) identified 20 putative genes in a 500-kb region of X-chromosome by sequencing four overlapping bacterial artificial chromosomes. Out of these, one possessed an ORF highly homologous with DNA-binding domain of the forkhead/HNF3/winged helix family of proteins. This gene in scurfy mouse was found to harbor a 2-bp insertion mutation, resulting in a truncated gene product, deleting the C-terminal forkhead domain (38). Investigators designated this gene as Foxp3. Functional complementation experiments by mating scurfy carrier females with Foxp 3 transgenic lines resulted in complete rescue of the scurfy phenotype, corroborating Foxp3 mutation as the cause (38).

At around same time, mutations in FOXP3 gene and its 3' untranslated region were confirmed in human patients of IPEX syndrome $(39,40)$. IPEX syndrome is immunodysregulation polyendocrinopathy enteropathy X-linked, originally described in 1982 by Powell et al. (41). The striking similarity in autoimmune phenotype of IPEX patients, scurfy and 3dTx mice led several groups to examine the function of Foxp 3 in Tregs. Subsequently, in 2003, three studies reported that indeed Foxp3 is uniquely expressed by $\mathrm{CD} 4^{+} \mathrm{CD} 8^{-} \mathrm{CD} 25^{+}$thymocytes and $\mathrm{CD}^{+} \mathrm{CD} 25^{+}$peripheral regulatory $\mathrm{T}$-cells $(42-44)$ in mice. Retroviral transduction of Foxp3 induced CD25 expression in $\mathrm{CD} 4^{+} \mathrm{CD} 25^{-} \mathrm{T}$-cells which were functionally suppressive and expressed Treg associated molecules CTLA4 and GITR. Deletion of Foxp3 in mice resulted in lymphoproliferative disorder identical to scurfy mice $(43,44)$. Mixed bone marrow chimera experiments demonstrated that indeed only Foxp3-sufficient bone 
marrows were capable of generating $\mathrm{CD} 4{ }^{+} \mathrm{CD} 25^{+}$Tregs (44). Conclusive evidence for Foxp3 as lineage specific marker for mice Tregs came from Foxp $3^{\text {eGFP }}$ reporter mice (45) in which GFP expression was found only in TCR $\beta^{+}$T-cells among all hematopoietic cellular compartments. Conditional deletion of Foxp3 in CD $4^{+}$T-cells led to a lymphoproliferative disorder mirroring scurfy phenotype. These series of experiments established Foxp3 as the molecular identity responsible for implementing Treg transcriptional signature. Further investigations revealed that the Foxp3 gene itself is regulated by three conserved noncoding sequences (CNS) 1-3. Detailed epigenetic analyses have identified CNS1 as the TGF $\beta$ responsive element which is required for peripheral generation of Tregs, CNS2 is involved with heritable maintenance of Foxp3 expression while CNS3 acts as a pioneering element for thymic induction of Foxp3 (46). Proteomic analyses demonstrated Foxp 3 to be interacting with more than 350 proteins in multiprotein complexes, many of which are transcription-related factors (47). A detailed review on regulation of Foxp3 and Foxp3 mediated regulation of the Treg transcriptome can be found in Lu et al. (12).

\section{DEVELOPMENTAL AND PHENOTYPIC DIVERSITY IN TregS}

Neonatal thymectomy experiments in mice confirmed beyond doubt that early development of Tregs happens in thymus. A detailed discussion on thymic development of Tregs can be found in Ref. $(13,48,49)$. Briefly, cell surface markers indicative of strength of TCR interaction (CD25, CD5, etc.) suggested the involvement of TCR signaling. TCR repertoires of Tregs have limited overlap with that of non-Tregs and are largely self-reactive (50). Nur77-GFP reporter mice which express GFP under Nur77 gene locus, an early gene expressed upon TCR stimulation have higher GFP expression in thymic Tregs (tTregs) (51). With regard to cytokines, it was reported earlier that mice lacking either IL2 or CD25 (45) are able to generate Tregs, albeit at a reduced level. However, if common $\gamma$ chain is deleted, Tregs are not formed (45). This suggests cooperation among $\gamma$ chain cytokines in Foxp3 expression and maintenance. Thus, the current model of Treg generation in thymus gravitates toward an instructive one wherein TCR signaling substantially above the strength required for positive selection and relatively near the strength that induces negative selection initiates specification toward pre-Treg state. In the second step, cytokines induce Foxp3 expression. More recently, Satb1, a genome organizer and transcription factor was shown to at least partially mediate the genomic arrangement of super-enhancers responsible for Treg development (52). The Treg specific super-enhancer patterns were found "poised" for activation even in conventional peripheral T-cells.

Though thymic regulatory $\mathrm{T}$-cells are adept at suppressing autoimmune responses against self-antigens, a reasonably tolerant immune environment cannot be developed if repeated immune responses are mounted against beneficial and innocuous microbes as well as food antigens. In part, this is achieved by generation of Tregs in the periphery. Indeed, initial evidences suggested that Tregs can be generated by oral antigen feeding
$(53,54)$ as well as by antigen-specific APCs $(55)$ in the absence of functioning thymus. Also, conventional $\mathrm{CD} 4^{+} \mathrm{CD} 25^{-}$naïve $\mathrm{T}$-cells could be converted to $\mathrm{CD} 4^{+} \mathrm{CD} 25^{+} \mathrm{CD} 45 \mathrm{RB}^{-/ \text {low }}$ suppressor cells by costimulation with TCR and TGF $\beta$. TGF $\beta$ activates Smad 2 and 3 transcription factors (56) which redundantly, help in peripheral Treg generation by initiating a cascade of interactions with specific enhancer regions within the Foxp3 locus (56-58).

Contrary to initial interpretations of Tregs being a universal immunosuppressive population, diligent interrogations led to identification of a rather diverse and distinct pool of heterogenous subsets. Other than the site of induction, Tregs were classified into two separate populations: central Tregs (cTregs) and effector Tregs (eTregs) $(59,60)$. cTregs are comparatively quiescent Tregs in the lymphoid tissues. They express the lymphoid homing molecules CD62L and CCR7 and are dependent on IL2 secreted by Tconv in T-cell zones of lymphoid tissues (60). On the other hand, eTregs are primarily non-lymphoid Tregs which downregulate lymphoid homing molecules and upregulate CD44, ICOS, GITR, and other activation-induced markers. For maintenance, they are dependent on sustained ICOS signaling (60). Most of these cells express transcription factor BLIMP1 and produce high IL10, akin to a population of ICOS $^{+}$IL $10^{+}$Tregs in humans (61).

Investigations into Treg mediated suppression of distinct helper T-cell immune responses imply a contextual Thelper-Treg coupled viewpoint of Treg heterogeneity. It was reported that Tregs express high amount of the interferon (IFN) regulatory factor IRF4, Treg specific ablation of which resulted in selective Th2 related pathologies (62). These findings initiated similar investigations in other helper T-cell contexts and indeed, now a well-established paradigm exists wherein, in a Th1 inflammatory context Tregs express transcription factor Tbet, responsible for Th1 speciation, and express CXCR3 to accumulate at such sites (63). Transcription factor STAT3 is expressed in Tregs in a Th17 context (64) which helps in upregulation of CCR6 to migrate to intestine and production of IL10 (65). Similarly, Bcl6 expression in Tregs was shown to be important for regulating Tfh cells and expression of CXCR5 $(66,67)$.

Moving a step further and increasing complexity and diversity among Tregs, several Treg subpopulations are discovered in non-lymphoid tissues. These Tregs are not only found to be instrumental in suppression of inflammatory responses but also integrate into a larger biological paradigm for the benefit of organ and organismal homeostasis. In the following sections, we will review the characteristics of non-lymphoid Tregs, how they originate and function in maintaining homeostasis of tissues. We will attempt to elucidate if, apart from location, these cell types can be further identified by virtue of tissue-specific phenotypic and functional characteristics. We will elaborately discuss the well-characterized Treg populations in adipose tissues (AT), intestines, and skin, as well as attempt to highlight upon some of the recently identified ones in other tissues like muscles, lungs, and placenta. While overzealous Tregs in malignancies not necessarily can be clubbed with normal tissue Tregs, but at certain level, as Tregs perceive the context of the environment they reside in and are hijacked by tumors for their benefit, we will also discuss tumor infiltrated Tregs in order to 
elucidate on the general principles that might integrate such heterogeneity.

\section{FAT Tregs: IMMUNOSUPPRESSION FOR METABOLIC HOMEOSTASIS}

Adipose tissue is natural calorie reservoir of the body. Overall, the tissue is classified as two somewhat functionally antagonistic tissue types: white adipose tissue (WAT) and brown adipose tissue (BAT). WAT stores the excessive nutrients in the form of fat droplets during over-nutrition and releases it under energy deficit conditions. BAT, by virtue of higher expression of the uncoupling protein 1 (UCP1) protein, enhances energy utilization by non-shivering thermogenesis (68). WAT is abundantly available and found mainly in subcutaneous tissue, omenta, mesenteries, perirenal tissues, and bone marrow, while BAT has a restricted distribution occurring mainly in interscapular and inguinal regions.

\section{AT Architecture}

Structurally, AT is a loose connective tissue comprising mainly of fat cells (adipocytes), each surrounded by its own basal lamina and separated by a thin layer of extracellular matrix composed of reticular and collagen fibers and supplied with numerous capillaries. Several other resident as well as transient cells are strewn around in AT namely fibroblasts, myofibroblasts, and immune cells like macrophages, mast cells, eosinophils, neutrophils, and T-cells. WAT are the professional fat depots (69) which store excess energy as triglycerides without the common lipotoxicity experienced by other cell types (70). WAT adipocytes are usually spherical with a single fat droplet occupying $90 \%$ cell volume and a thin elongated mitochondrion on one side. On the other hand, BAT integrates environmental conditions via brain adrenergic responses toward cold temperatures. Adipocytes in BAT are typically polygonal, containing triglycerides in multiple small vacuoles, and are characterized by numerous large, spherical mitochondria.

\section{Fat Treg Origin and Accumulating Factors}

The plethora of adipokines and cross-talk with nervous as well as immune system has underscored the importance of AT as an endocrine organ with profound effects on body's metabolic homeostasis. However, as adipocyte increase in size due to excess calories, hypoxia sets in leading to accumulation of inflammatory macrophages (Figure 1) in obese adipose (71). Subsequent upregulation of several inflammatory adipokines (72) can activate $\mathrm{CD}^{+}{ }^{+} \mathrm{T}$-cells independent of macrophages. Any immune response shall be regulated so that it does not outlive its utility; a task largely achieved by several anti-inflammatory immune cell types already resident in the adipose (73-77).

In a seminal study, Feuerer et al. (76) identified unique fatresiding Tregs in mouse and human ATs. Surprisingly, unlike peripheral lymphoid compartment where normally $10-15 \%$ of $\mathrm{CD}^{+}{ }^{+} \mathrm{T}$-cells are Foxp $3^{+}$Tregs, almost half of the fat $\mathrm{CD} 4^{+} \mathrm{T}$-cells are Foxp $3^{+}$Tregs, which were found to accumulate primarily in visceral fat over a period of time since birth, peaking at around

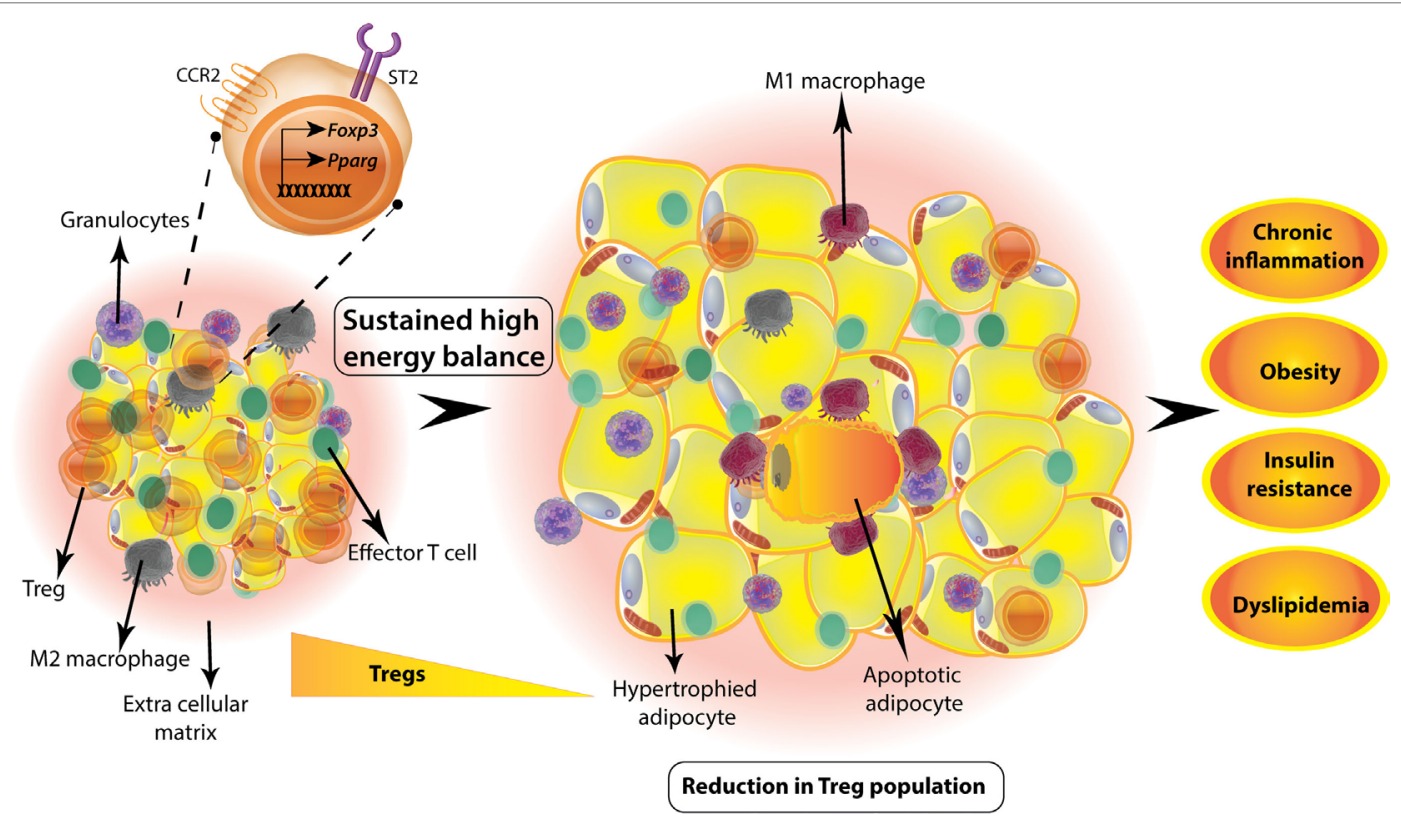

FIGURE 1 | Visceral white adipose tissue (WAT) regulatory T-cells (Tregs) are involved in metabolic homeostasis. WAT Tregs adapt to adipose environment by expression of PPAR $\gamma$ that regulates genes involved in lipid metabolism. These Tregs also express alarmin IL33 receptor ST2 and adipose chemokine receptor CCR2. Tregs are abundant in lean adipose tissue of adult mouse; however, if there is a sustained positive energy balance as in high-fat diet-induced obesity animal model, then the Treg numbers decrease drastically. This is concomitant to a change in macrophage phenotype from anti-inflammatory M2 to inflammatory $\mathrm{M} 1$ macrophages and unhealthy hypertrophy of adipocytes. Sustained hypertrophy leads to adipocyte apoptosis and exacerbated inflammation. Overall, decrease in adipose Tregs is accompanied by obesity, insulin resistance, dyslipidemia, and chronic low-grade inflammation. 
25 weeks of age. In one study, this characteristic accumulation of Tregs was found to be accompanied by a sudden drop to fifth week levels (78) in mice aged further, suggesting a negative correlation between the frequency of visceral WAT resident Tregs and age-related metabolic inflammation (Figure 2). In contrast to this finding, a recent study, reported even greater accumulation of Tregs in older mice, implicating an alternative viewpoint instead (79) (Figure 2). The cause of this discrepancy might be different colonies, husbandry practices, as well as microbial and dietary composition. Nonetheless, the aged visceral WAT Tregs were found to be functional (79).

As far as origin of AT Tregs are concerned, visceral WAT Tregs appear to be largely of thymic origin. A thymectomy beyond 3 weeks of life does not affect visceral WAT Tregs population in mice (80). TCR $\alpha$ sequencing experiments from "Limited" mice [mice with limited focused diversity restricted to CDR3 $\alpha$ (81)] showed that TCR repertoire of fat Tregs are different from conventional fat T-cells. Furthermore, visceral fat Treg repertoire was only a restricted subset of lymph node (LN) Tregs TCR repertoire (76), suggestive of an abdominal WAT specific distinct TCR repertoire of Tregs. This indicates either a continuous supply of Tregs from peripheral LNs or an initial seeding of tTregs followed by selected clonal expansion in AT. Adoptive transfer of congenically marked Tregs confirmed that visceral WAT Tregs are not significantly derived from circulating Tregs (80). Also, very high expression of both Helios and Neuropilin1 (Nrp1) as well as transcriptomic analysis of visceral WAT Tregs suggest their thymic origin and little to no conversion of naïve T-cells into visceral WAT Tregs (80).

Origin of subcutaneous WAT Tregs and BAT Tregs have not been studied in much detail. Naïve T-cells isolated from both these tissues, however, produce significantly high number of induced Tregs than visceral WAT in in vitro conversion assays (82).

\section{Tissue Adaptation and Phenotype}

That extralymphoid Tregs adapt to the context and microenvironment is best explained by higher expression of transcription factor PPAR $\gamma$ in fat Tregs $(83,84)$. Co-immunoprecipitation studies confirmed PPAR $\gamma$ interaction with Foxp3, suggesting a visceral WAT-specific Foxp3-PPAR $\gamma$-mediated gene expression axis (83). Using a Blimp1-GFP reporter mouse, Vasanthkumar et al. (84) showed that most of the visceral WAT Tregs fall in the category of eTregs. For identifying the survival factors for eTregs, they reported that visceral WAT Tregs specifically express Illrll, which encodes alarmin IL33 receptor ST2. Both IL33 deficiency in general, as well as T-cell intrinsic ST2 deficiency resulted in specific reduction in number and percentage of visceral WAT Treg compartment (84). In in vitro settings, both IL2 and IL33
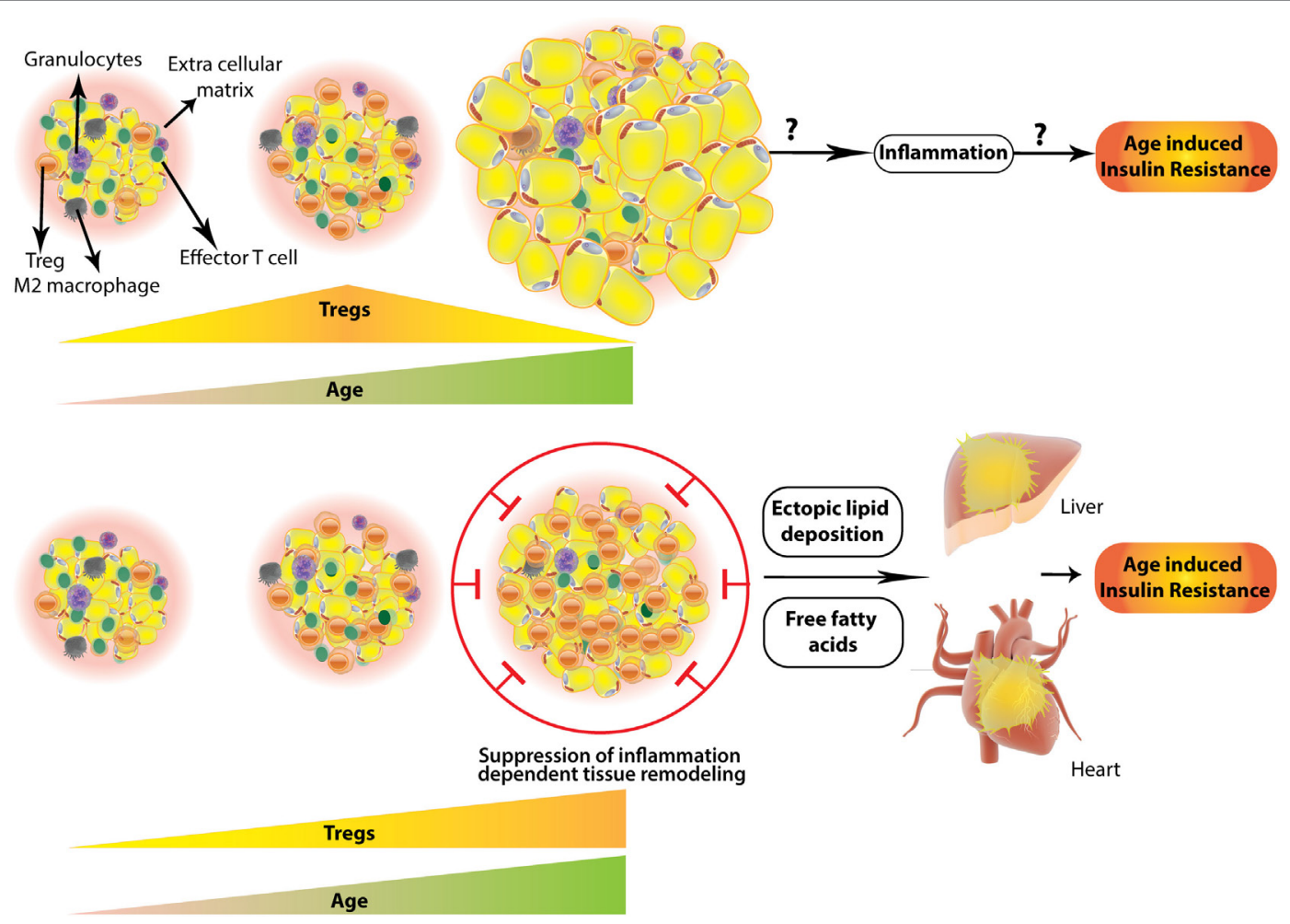

FIGURE 2 | Two contrasting scenarios of regulatory T-cells (Treg) numbers and their outcome in aged white adipose tissue (WAT). WAT Tregs increase with age reaching a plateau and then decrease abruptly in aged ( 45 weeks) mouse (top). Whether this results in inflammation leading to age-associated insulin resistance is not explored; however, (bottom part) contrasting evidence suggest that white adipose Tregs keep on increasing even in the aged adipose tissue, which in concordance with "adipose tissue expandability hypothesis" (see text) results in suppression of healthy inflammation required for remodeling of adipose. This results in a storage space problem leading to ectopic deposition of fat in visceral organs, like liver and pericardium. This is accompanied by free fatty acid induced lipotoxicity and age-associated insulin resistance. 
were able to induce proliferation and ST2 upregulation in a fraction of T-cells upon TCR stimulation which was dependent on MyD88 (84). Development and proliferation of visceral WAT Tregs appears to be dependent on two signals: (1) TCR crosslinking which induces PPAR $\gamma$ and ST2 expression via BATF and IRF4, both of which bind to the intronic regions of Pparg and Il1rl1 genes (84) and (2) IL33 which via MyD88 feeds forward the expression of ST2 (84). In accordance to the concept of local adaptation, PPAR $\gamma$ in visceral WAT Tregs upregulates the expression of lipid metabolism genes like Dgat1 (diacylglycerol $O$-acyltransferase 1 ), coding for an enzyme which catalyzes the terminal step in triacylglycerol synthesis by using diacylglycerol and fatty acyl $\mathrm{CoA}$ as substrates; and Pcyt1a (choline-phosphate cytidylyl transferase A), an enzyme involved in regulation of phosphatidylcholine biosynthesis (83). It is possible that these gene products enable visceral WAT Tregs to survive in a lipotoxic environment and/or enable the utilization of fatty acids as metabolic fuel. Other than these essential factors, visceral WAT Tregs also express high levels of GATA3, Klrg1, early activation marker CD69, and adipose signature chemokine receptor CCR2. BAT Tregs are found to be very similar to WAT Tregs at transcriptional level with higher expressions of PPAR $\gamma$, IL10 and chemokine X ligands 1 and 2 (85). The under-expressed transcripts were those encoding for TCR signaling specific T Cell Factor 7 and cytokine IFN $\gamma$ (85).

\section{WAT Tregs Are Important Players in Metabolic Syndrome}

Adipose originated pro-inflammatory cytokines, like TNF $\alpha$, IL6, and type1 IFNs, have been suggested as causative of insulin resistance and metabolic syndrome (86-88). Also, human obese subjects were found to be deficient in circulating Tregs, whose levels were inversely correlated with body weight and BMI (89). Considering the primarily immunosuppressive phenotype of Tregs, it is expected that fat Tregs play a major role in controlling adipose inflammation, and in turn, affect the overall metabolic homeostasis of the body. Indeed, in Foxp $3^{\text {DTR }}$ mice, in which the gene encoding diphtheria toxin receptor (DTR) is knocked into the Foxp3 locus (90), Treg depletion upon diphtheria toxin (DT) administration, leads to visceral WAT tissue inflammation (76). However, total Treg deletion also initiates a strong systemic inflammatory response (90). Hence, a visceral WAT specific model for Treg deletion was required. This was achieved by Treg specific deletion of PPAR $\gamma$, which resulted in more than $80 \%$ reduction in visceral WAT Tregs, without any effect on splenic Treg population (83). This decrease in Treg population was accompanied with marked inflammatory cell infiltration in visceral WAT (83). In a high-fat diet-induced obesity model, WAT Treg numbers are reduced drastically (Figure 1), which can be rescued by treatment with a synthetic PPAR ligand pioglitazone, which improves insulin sensitivity by working on PPAR $\gamma 1$ and 2 and affecting lipid metabolism (91). Its administration was able to improve the metabolic parameters in wild-type mice but not in mice harboring PPAR $\gamma$ deficient Tregs, suggesting a direct role of PPAR $\gamma$ expression in visceral WAT Tregs.
Interestingly, the role of visceral WAT Tregs in aging animals has been reported to be opposite to what was observed in comparatively young animals. Contrary to obese animals, depletion of visceral WAT Tregs in aged animals improved the metabolic parameters and rescued aging induced insulin resistance (79) (Figure 2). Treg specific deletion of PPAR $\gamma$ led to less increase in fat and more in lean weight with age (more than 45 weeks). The adipocyte size was less and hepatic triglyceridosis was decreased. An increase in total Tregs by IL2-IL2 antibody immune complex resulted in reduced glucose uptake by aged adipocytes, suggesting compromised storage function (79). Similar results were obtained upon external IL33 administration. Overall this study reveals an unexpected cooperative role of visceral WAT Tregs in age-associated insulin resistance and metabolic inflammation. One explanation of this seemingly counter-intuitive finding might be extended by the so called "adipose tissue expandability" hypothesis. This hypothesis posits that in a state of "positive energy balance" metabolic complications arise because WAT is not able to expand further and accommodate excess calories, essentially propounding that metabolic syndrome coming out of excessive nutrition and obesity is actually a storage space problem (92). Indeed, animal models where AT inflammation is controlled result in decreased AT hyperplasia in a high-fat diet-induced mouse model of obesity (93), which causes ectopic lipid depositions (hepatic steatosis, dyslipidemia, etc.) and worsened metabolic parameters (93). Also, obese ob/ob mice which were made transgenic for full-length adiponectin and thus had adiponectin levels equivalent to treatment with a PPAR $\gamma$ agonist, showed uninhibited WAT expansion leading to morbid obesity but improved insulin sensitivity and other metabolic parameters (94) owing to reduced ectopic lipid deposition in liver and muscles (94). Given these observations, whether and how age-related accumulation of the visceral WAT Tregs results in compromised AT hyperplasia, remains to be seen.

\section{BAT Tregs Help in Thermogenesis}

A generalized Treg ablation alters the metabolic profile of mice with regard to BAT as well. DT mediated deletion of Tregs in Foxp $3^{\text {DTR }}$ mice resulted in reduced whole-body oxygen consumption in a short-term cold temperature exposure model (85). That the Tregs are at forefront of metabolic homeostasis and their interventions are highly context dependent is further strengthened by a recent study analyzing BAT Tregs in detail. While a short-term (2 weeks) high-fat high-sugar (HFHS) diet, promoting thermogenesis (95), increased BAT Tregs, it actually decreased visceral WAT Tregs in young adult mice (82). On the contrary, a long-term HFHS diet (16 weeks) significantly reduced visceral WAT Tregs but made no impact on percent of BAT Tregs. This suggests that the tenor of caloric intake can have specific effect on tissue Tregs. In accordance to the role of BAT Tregs in non-shivering thermogenesis, treatment with ADRB3 ( $\beta$-3 adrenergic receptor) agonist increased Tregs in BAT. However, "betaless" mice which are deficient in all three $(\beta-1,2$, and 3 adrenergic receptors) did not have a reduced percentage of BAT Tregs, suggesting a redundant role of adrenergic signaling in BAT Treg accumulation per se. Treg depletion, followed by $\beta-3$ stimulation on the other hand did result in reduced levels 
of BAT thermogenic and lipolytic genes (Ucp1, Ppargc1a, Pparg, Prdm16, Lpl, etc.) confirming Treg functionality in BAT thermogenesis (82). It will be interesting to know if this results in reduced metabolic adaptation in cold exposure. Also, whether these effects are intrinsic to Tregs can only be ascertained with Treg specific Adrb3 deletion. Thus, these studies confirm a role of Tregs in BAT which goes beyond immunosuppression and actively associates Tregs with cold adaptations of the body by regulating lipolysis and thermogenesis.

\section{INTESTINAL Tregs: PRESERVING THE HOLOBIONT}

The mammalian digestive system performs two very vital functions-digestion and absorption of food and shaping a gut microbial ecosystem. According to recent estimates, human colon harbors about $4 \times 10^{13}$ bacteria $(96,97)$, a density $\left(10^{11} / \mathrm{mL}\right)$ highest among any microbial habitat (98). It has a perplexing task to efficiently implement a "goldilocks" balance between two seemingly opposite events; permit absorption of nutrients but check exposure to harmful substances, guard against invasive pathogens but facilitate colonization of commensals and help them thrive.

\section{Architecture}

Incessant provision of food and microbial antigens has resulted in typical structural adaptations in gut $(99,100)$ and evolution of specialized gut immune cells for immunosurveillance and maintenance of tolerance (101). The small intestine (duodenum, jejunum, and ileum) with maximum absorptive surface created by large circular folds (plicae) and finger like projections (villi and microvilli), has evolved as the primary organ for food absorption. The folding results in formation of deep invaginations, crypts of Lieberkühn, which house Paneth cells that secrete antimicrobial molecules upon exposure to bacterial antigens. Several enteroendocrine cells and mucus producing Goblet cells are also interspersed among small intestinal epithelial cells. The large intestine (cecum, colon, and rectum) harbor majority of commensals and perform the vital functions of absorbing water and vitamins while converting the undigested food into feces. The large intestinal walls are protected from luminal contents by two layers of mucus, the outer (luminal) thin mucus layer which hosts most of the bacteria, and the inner thick mucus layer which is largely sterile $(102,103)$.

Histologically, intestinal tract contains four layers-mucosa, submucosa, muscularis propria, and adventitia or serosa. The mucosa is the layer where most of the immune processes take place. It consists of an epithelial layer, which has scattered intraepithelial lymphocytes (IELs), underlying lamina propria (LP) and a thin muscle layer muscularis mucosa. The LP consist of non-cellular connective tissue, like collagen and elastin, blood and lymphatics, myofibroblasts, and nerve endings, and is densely packed with immune cells including mononuclear cells, plasma cells, B and T lymphocytes including Tregs, eosinophils, macrophages, and mast cells (104).
Different parts of intestine drain into separate LNs, like duodenum drains into a $\mathrm{LN}$ embedded in pancreatic tissue; mesenteric LNs drain jejunum, ileum, cecum, and ascending colon; two small LNs in pancreatic tissue drain transverse colon and descending colon and rectum primarily drains to caudal LNs (101). Anatomic variations largely define the antigenic variations of intestine as well. While small intestine grapples for equilibrium against food antigens, large intestines have an overwhelming load of microbial antigens. As much as these are foreign to the body, they are equally essential. Thus, for the economy of immune response it is highly desirable to assimilate those in the immunological self. The intestinal population of Tregs is arguably the most important cell type to contain the immune response against both food and innocuous microbial antigens and maintenance of intestinal homeostasis $(105,106)$.

\section{Origin of Intestinal Tregs}

Like other non-lymphoid tissues, Tregs are also enriched in intestinal LP with colon harboring 25-35\% (107-109) and small intestine harboring $10-15 \%(109,110)$ Tregs among total CD4 ${ }^{+}$ T-cells. Apropos to the prevalent inflammatory milieu and antigenic environment, the colonic Tregs are largely developed against microbial antigens. GF mice, devoid of any microbiota, have several folds less number of colonic Tregs compared to specific pathogen-free (SPF) mice (111, 112). A long-term broad-spectrum antibiotic treatment also reduces colonic Tregs in SPF mice (111). As small intestine is seat for nutrient absorption, most of the small intestine LP (siLP) Tregs do not develop against bacterial antigens as evident by comparable number of Tregs in SPF and GF mice (109). However, once the GF mice are brought up as antigen-free (AF) mice by provision of only elemental diet post-weaning, there is a marked decrease in siLP Tregs (109). A subset of Tregs, however, remains in colon as well as small intestine of GF and AF mice, presumably specific to gastrointestinal self-antigens.

Sequencing of colonic Treg TCRs of genetically engineered mice with limited polyclonal repertoires found that TCR usage of colonic Tregs was different from that of other tissues (113). Also, there was very little similarity of TCR usage between Tregs and naïve or effector Foxp3 $3^{-}$T-cells (113). Stable chimeras made from retroviral transduction of colonic Treg TCRs to bone marrow progenitors resulted in induction of respective TCR expressing Tregs preferentially in colon while no specific TCR bearing cells were found in thymus (113). Adoptive transfer of naïve T-cells from the transgenic lines made from colonic TCRs resulted in very efficient conversion to peripherally induced Tregs (pTregs) in mesenteric LNs and colon (114). Other than the specific TCR repertoire, high surface expression of Helios, an Ikaros family transcription factor (115), and Nrp1, a membrane-bound co-receptor for vascular endothelial growth factor and semaphorin $(116,117)$, has been found to be associated with tTregs. Although the precise origin of Tregs based on these markers is debatable since their expression can be upregulated in inflammatory settings $(118,119)$, nevertheless, most of the studies have reported enrichment of $\mathrm{Helios}^{-}$and/or $\mathrm{Nrp1}^{-}$pTregs in colonic Treg compartment $(107,114)$. Also, the frequency of colonic Foxp $3^{+} \mathrm{Helios}^{-} \mathrm{Nrp}^{-}$Tregs is significantly reduced in GF mice 
compared to SPF mice (116). Furthermore, treatment of SPF mice with broad-spectrum antibiotics decreased the Helios ${ }^{-}$colonic Tregs (111). Molecular studies on Foxp3 gene locus have identified an enhancer, CNS1, to have a prominent role in pTreg generation in gut-associated lymphoid tissues (46). CNS1 contains a TGF $\beta$ NFAT response element (46) and binding sites for retinoic acid receptor (RAR) and retinoid X receptor heterodimer, receptor for retinoic acid (RA) (120). It has been shown that TGF $\beta$ and RA can induce de novo generation of pTregs upon antigen activation via $\mathrm{CD}_{103}{ }^{+} \mathrm{DCs}(121,122)$ (Figure 3). Indeed, CNS1-deficient mice have fewer LP Tregs at weaning (46). However, it was recently reported that CNS1 deficiency in colonic TCR transgenic T-cells only delays the pTreg generation and ultimately T-cells do convert to Foxp3 $3^{+}$Tregs (114).

While pTregs are largely accepted to be the primary source of intestinal Treg population, at least under an experimental setting where generation of extra-thymic Tregs are compromised, thymically generated Tregs can migrate to intestinal LP and proliferate to fill up the niche (Figure 3). It has been reported that in a limited TCR model, the TCR repertoire of tTregs and colonic Tregs overlap considerably (123). Another study utilizing K14$\mathrm{A} \beta \mathrm{b}$ (Keratin 14 transgenic, K14) mice, which have restricted MHCII expression in thymic cortical epithelium and thus, cannot provide peripheral MHCII signals for extra-thymic Treg

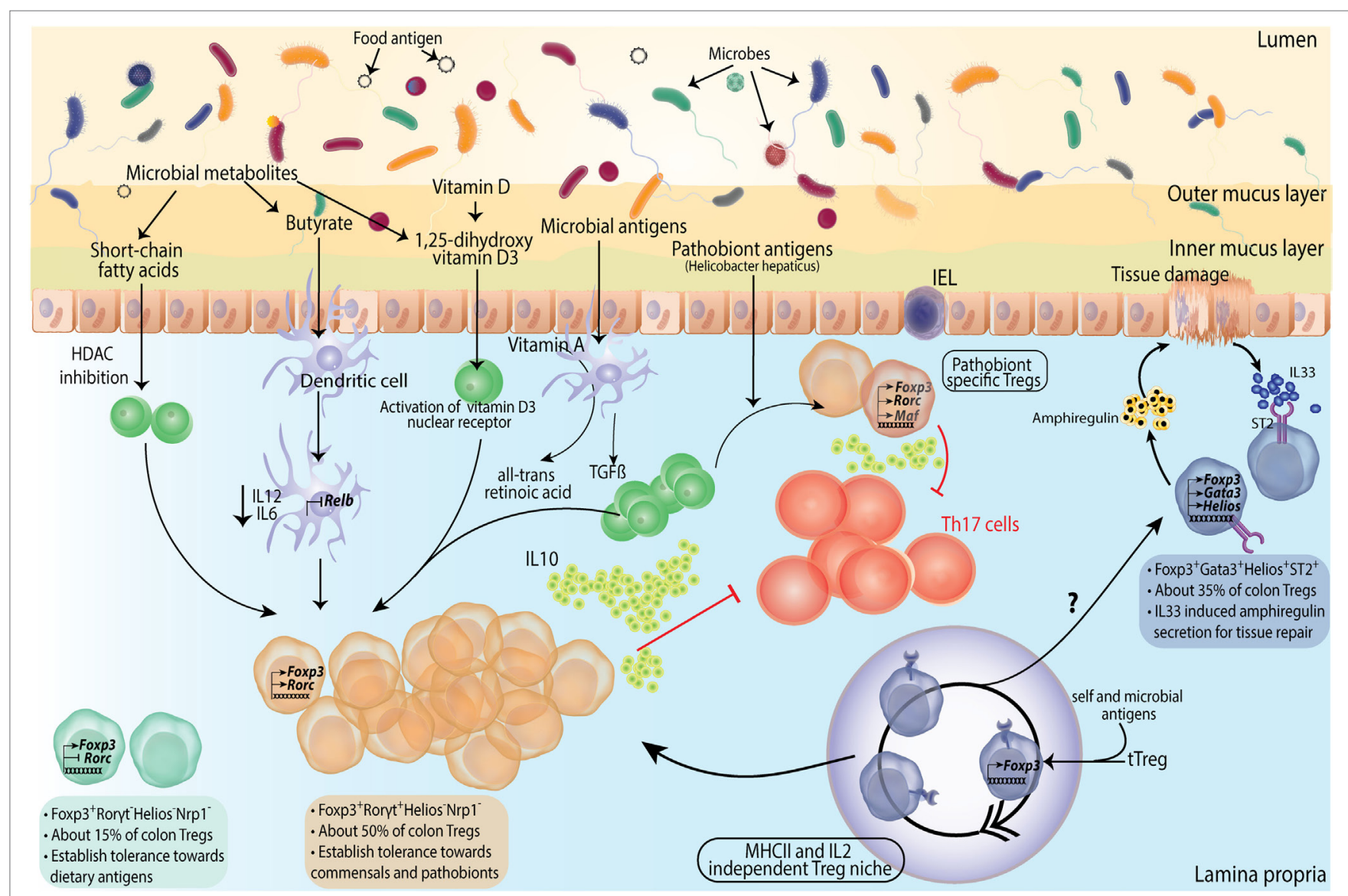

FIGURE 3 | Subtype differentiation of regulatory T-cells (Tregs) in large intestine. Colonic Tregs differentiate into three different subtypes based on RORyt (Rorc) and GATA3 expression along with Foxp3. Foxp3 ${ }^{+}$ROR $\gamma t^{-}$cells comprise 15\% of colonic Tregs, their function in colon is not much elucidated but presumably these are responsible for establishing tolerance to dietary antigens. Second and major subset of colonic Tregs is Foxp3+ROR $\mathrm{ft}^{+}$Tregs, constituting about $50 \%$ of total colonic Tregs. These cells are primarily involved in microbial tolerance and several mechanisms contributing to their generation has been described. From left, short chain fatty acids generated by microbial fermentation can differentiate naive T cells into Foxp3 ${ }^{+} R O R \gamma t^{+}$Tregs in lamina propria (LP). Butyrate, specifically, can contribute to Foxp3 expression and function by virtue of its histone deacetylase (HDAC) inhibitory function, as well as can turn dendritic cells (DCs) into Treg generating tolerogenic cells by suppressing their IL12 and IL6 levels and expression of NFkB subunit Relb. Vitamin D metabolite 1,25-dihydroxy vitamin D3 differentiates naive T cells into Tregs by activating its nuclear receptor. TGF $\beta$ along with DC generated vitamin A metabolite all-trans retinoic acid differentiates naive $T$ cells into Tregs in presence of microbial antigens. Foxp3+ROR $\mathrm{t}^{+}$Tregs deploy various mechanisms toward establishing dominant tolerance with IL10 production and direct suppression of Th17 cells as prominent ones. A special subset of Foxp3+ROR $\gamma \mathrm{t}^{+}$Tregs express cMAF and is instrumental in establishing tolerance to pathobionts in homeostasis. Foxp $3^{+} \mathrm{ROR} \mathrm{rt}^{+} \mathrm{CMaf}{ }^{+}$Tregs are identified against specific epitopes of Helicobacter hepaticus and suppress epitope specific Th17 cells. It has been shown that in absence of pTregs, early seeding of thymic Tregs (tTregs) happens in colonic LP. These tTregs expand into a niche which is independent of MHCII and IL2 signaling but depends on microbial antigens. These Tregs subsequently fill up the LP Treg compartment. However, whether these can differentiate into all Treg subtypes is not known. A third subtype of Tregs express GATA3 (not ROR $\gamma$ t) and constitutes about a third of total Tregs. These Foxp3 $3^{+}$GATA3 ${ }^{+}$Tregs express ST2 receptor which bind to tissue damage-induced alarmin IL33. Foxp3+GATA3 $3^{+}$Tregs are instrumental in suppressing inflammation and facilitating tissue repair by secretion of amphiregulin upon tissue damage. 
generation, showed that while Treg population was significantly decreased in mLNs and spleen, the intestinal Treg compartment was rather intact (124). The LP Treg niche of these mice was found to be inhabited by Tregs of thymic origin at young age. This niche filling phenomenon was not IL2 dependent but was induced by microbial presence, as broad-spectrum antibiotic treatment decreased both large and siLP-Tregs (siTregs) (Figure 3). At an older age however; newly generated tTregs were excluded from the LP, presumably due to already occupied Treg niche (124). Taken together, therefore, the available data suggest a peripheral origin of majority of intestinal Tregs and thymic origin of a small subset. However, these mechanisms of origin and development cannot be mutually exclusive and contributions from different pathways are likely to fine tune the ultimate composition of the intestinal Treg compartment.

\section{Tregs Specialize into Multiple Subsets in Intestines}

Transcriptomic and functional analyses of intestinal Tregs have largely identified three specialized subsets. Based on transcription factor and surface molecular expression these subsets are $\mathrm{GATA}^{+} \mathrm{Helios}^{+}\left(\mathrm{Nrpl}^{+}\right)$, retinoic acid receptor related orphan receptor $\gamma \mathrm{t}(\mathrm{ROR} \gamma \mathrm{t})$ expressing $\mathrm{ROR} \gamma \mathrm{t}^{+} \mathrm{Helios}^{-}$and $\mathrm{ROR} \gamma \mathrm{t}^{-}$ $\mathrm{Nrp1}^{-}\left(\right.$Helios $\left.^{-}\right)$subsets (Figures 3 and 4A).

GATA3 is expressed by about a third of intestinal Tregs and can be induced in $\mathrm{CD}^{+}{ }^{+}$Foxp $3^{+}$Tregs upon TCR engagement (110). That most of these Tregs are Helios ${ }^{+}$and are unaffected by microbial presence suggests their thymic origin (107). However, upon TCR engagement, GATA3 can be induced in CD4+Foxp3 ${ }^{-}$ naïve T-cells as well, in both in vivo and Treg polarizing in vitro settings (110). While expression of GATA3 is not required under homeostatic conditions, under inflammatory conditions lack of GATA3 in Tregs hampers their accumulation at inflammatory sites (110). GATA3 and Foxp3 interact both at protein and gene levels in Tregs (47). GATA3 binds to Foxp3 locus and its deletion in Tregs reduces Foxp3 expression $(47,125)$. It occupies significant number of genes, which are direct targets of Foxp3 and thus, collaborates with Foxp3 to establish Treg gene expression program. Indeed, Treg-specific GATA3 deletion results in intestinal pathology with heightened Th2 cytokine production from large intestinal effector T-cells (47). Most of the GATA3 ${ }^{+}$Tregs in colon express ST2, which is regulated by GATA3 expression in a feed-forward manner (108). Alarmins like IL33 are produced upon local tissue damage $(126,127)$ and thus limit self-injury in part by activating GATA $3^{+}$ST2 ${ }^{+}$Tregs (108). ST2 ${ }^{+}$Tregs show enhanced production and activation of IL10 and TGF $\beta$ (128). IL23 on the other hand appears to regulate the effect of IL33 in thymus-derived Tregs via STAT3 signaling (108).

$\mathrm{CD}^{+}{ }^{+} \mathrm{Foxp}^{+}{ }^{+} \mathrm{ROR} \gamma \mathrm{t}^{+}$Tregs in the intestine are another subset of Tregs specialized toward microbial immunity. These comprise about $50 \%$ of total Tregs in colon, which are readily lost in GF mice or upon antibiotic treatment $(107,129)$ (Figure 3). A small population consisting of about $10-15 \%$ of Tregs is also found in small intestine (107) (Figure 4). Most of the ROR $\gamma \mathrm{t}^{+}$Tregs do not express Helios $(107,129)$ or $\operatorname{Nrp} 1$ (130), suggestive of their
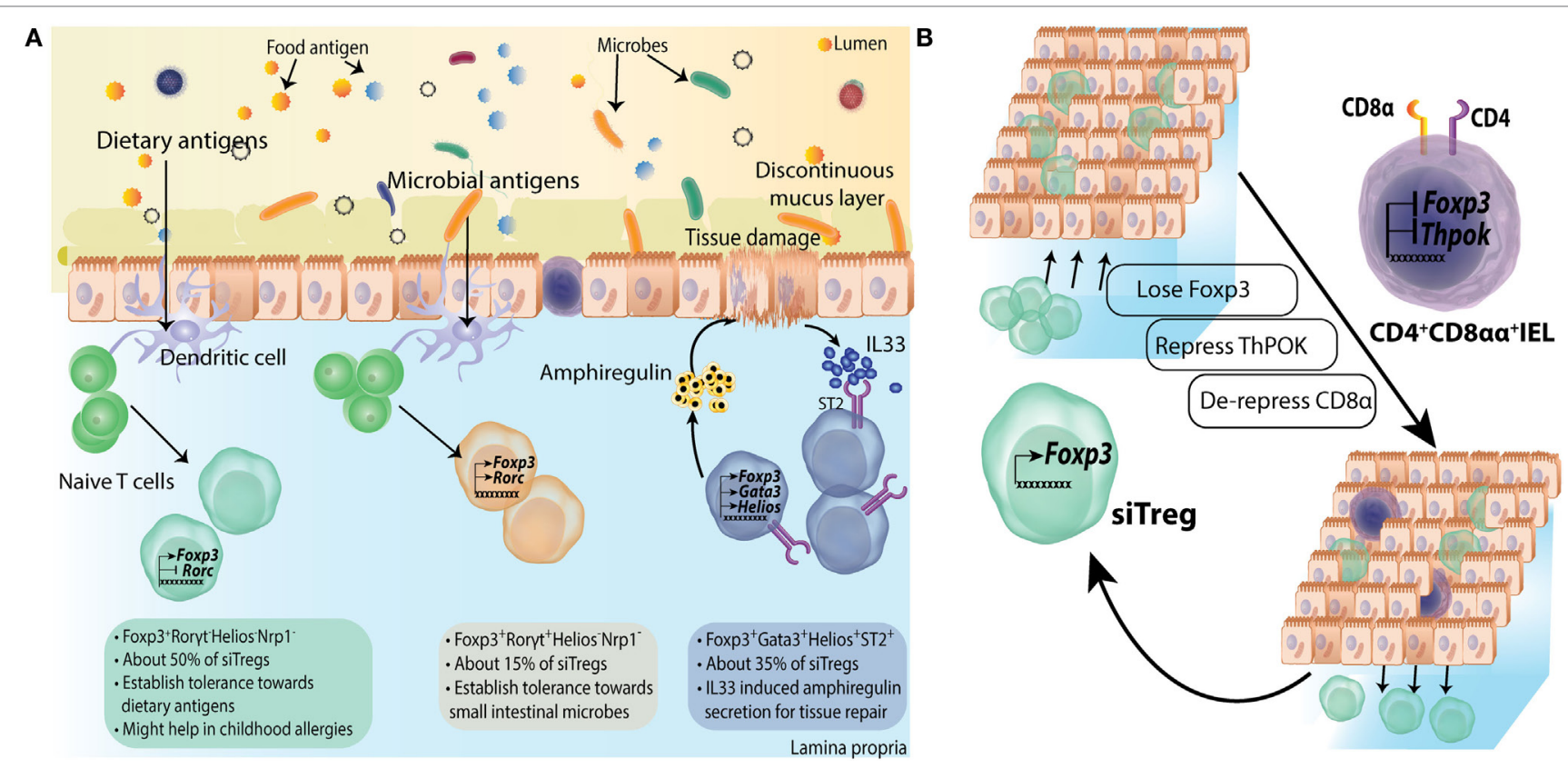

FIGURE 4 | Subtype differentiation of regulatory T-cells (Tregs) in small intestine. (A) Small intestine lamina propria (LP) Tregs are differentiated into all three subtypes mentioned in Figure 3; however, Foxp3+ROR t $^{-}$Tregs are primary population forming about 50\% of siTreg compartment. They are primarily generated in response to dietary macromolecules and are proposed to be helpful in containing childhood allergies. Foxp3 ${ }^{+} \mathrm{ROR} \mathrm{t}^{+}$and Foxp3 ${ }^{+} \mathrm{GATA} 3^{+}$Tregs are about $15 \%$ and $35 \%$ of total siTregs, respectively. (B) Some siTregs continuously traverse in and out of small intestinal epithelial compartment. While most of these Tregs return back to LP, a fraction of these lose their Foxp3 expression and repress ThPOK expression inside epithelial layer. They subsequently, de-repress CD8a locus to convert into CD4 ${ }^{+} \mathrm{CD} 8 \alpha \alpha^{+}$double positive intra epithelial lymphocytes. 
extra-thymic origin. However, these cells have substantially reduced $\mathrm{CpG}$ methylation within the CNS2 enhancer region of Foxp3 locus, which is known to be well correlated with stable Foxp3 expression $(130,131)$. Not all bacteria can elicit similar population of ROR $\gamma \mathrm{t}^{+}$Tregs, as it was found that a gradation of Treg inducing capacity exists (107). Mechanistic insights on why certain bacteria have superior capacity of inducing intestinal Tregs than others have started to emerge only recently. It has been reported that short chain fatty acids produced upon fermentation of starch and other dietary fibers by clostridia strains, mainly butyrate and propionate but not acetate, can contribute to colonic Treg generation. Mechanistically, this is attributed to their histone deacetylase inhibitory properties (132) resulting in increased acetylation of Foxp3 locus $(133,134)$ (Figure 3). Apart from directly acting on T-cells, butyrate also affects DC ability to induce Treg differentiation. Knockdown of Relb, which encodes NFKB subunit, has been shown to generate tolerogenic DCs by inhibiting their maturation $(135,136)$. Indeed, in vitro treatment with butyrate represses lipopolysachharide response genes, including Il12, Il6, and Relb in DCs (133) (Figure 3). On a translational note, in human IBD patients, colonic butyrate producing bacteria are decreased (137) and mucosal butyrate transporter, monocarboxylate transporter 1 , is downregulated (138). It is also possible that colonic Tregs are generated in an antigen-specific manner. Indeed, colonic Treg TCRs have been reported to interact with colonic bacteria in vitro (113). Very recently, colonic T cells with TCRs cognate to epitopes of a pathobiont Helicobacter hepaticus are shown to induce pTregs under homeostatic conditions (139). This study establishes the role of colonic pTregs in induction and maintenance of tolerance to pathobionts as well. Surprisingly, it was found that although such Tregs are $\mathrm{ROR} \gamma \mathrm{t}^{+}$, their major functional suppressive capabilities are implemented by expression of the transcription factor cMAF (139) (Figure 3). cMAF offsets Th17 polarization by producing IL10 downstream to TGF $\beta 1$-STAT3 signaling (140). H. hepaticus colonized mice with Treg specific Rorc deletion had no significant increase in colonic Th17 cells while mice with Treg specific Maf deletion had significantly high Th17 cells (139). Thus, ROR $\gamma \mathrm{t}^{+}$ pTregs in colon establish tolerance to commensals as well as pathobionts and suppress inflammation in a cMAF-dependent manner.

The third Treg subtype $\left(\mathrm{CD} 4^{+}\right.$Foxp $\left.3^{+} \mathrm{ROR} \gamma \mathrm{t}^{-}\right)$was identified very recently. Most of these cells express low levels of Nrp1 and thus are, supposedly, pTregs. These cells constitute about $50 \%$ of siLP Tregs and 15\% of colonic Tregs (109) (Figures 3 and 4A). Their localization suggests that these are primarily generated against dietary antigens. Indeed, long-term antibiotic treatment of SPF mice could not reduce their numbers in intestine while $\mathrm{ROR} \gamma \mathrm{t}^{+} \mathrm{Nrp} 1^{\text {lo }}$ pTregs were reduced several folds. On the other hand, weaning SPF mice onto AF diet dramatically reduced ROR $\gamma \mathrm{t}^{-} \mathrm{Nrp} 1^{-}$pTregs (109). Adoptive transfer of naïve OTII CD4 ${ }^{+}$T-cells in mice on AF diet primarily elicits Th1 cell immune response while Th17 and Th2 responses were comparable to SPF animals. However, pTregs generated in this model were primarily ROR $\gamma \mathrm{t}^{+} \mathrm{Nrp}^{-}$pTregs, suggesting that dietary antigens can also generate $\mathrm{ROR} \gamma \mathrm{t}^{+}$pTregs in the absence of microbiota (109).
While TGF $\beta$ is by far the most important factor as far as generation and intestinal accumulation of pTregs is concerned (141-143), a generalized modulation of intestinal pTregs can be achieved by several other factors like dietary vitamin A, vitamin D, Niacin (Vitamin B3), Folic acid (Vitamin B9), and tryptophan [reviewed in Ref. (144)]. All-trans retinoic acid, a metabolite of Vitamin A, produced by DCs facilitates de novo generation of Foxp $3^{+}$Tregs from naive $\mathrm{CD} 4^{+} \mathrm{CD} 25^{-}$T-cell populations in mice $(121,145)$ (Figure 3$)$. It also plays an important role in upregulating gut-homing markers CCR9 and CD103 (integrin $\alpha \mathrm{E}$ ) on pTregs (146). Feeding mice with Vitamin A-deficient diet or treatment with RAR inhibitors reduces the ROR $\gamma \mathrm{t}^{+}$pTregs in colon while GATA3 ${ }^{+}$Tregs are not affected (129). Similarly, $\mathrm{ROR} \mathrm{t}^{-} \mathrm{p}$ Tregs in small intestine are also not affected by vitamin A or RA (109). Vitamin D metabolite 1, 25-dihyroxyvitamin D3 binds to Vitamin D3 nuclear receptor in CD4 ${ }^{+}$T-cells and promotes Foxp3 expression (147) (Figure 3). Recently, it was shown that in human patients of ulcerative colitis a Vitamin D3 agonist can convert CD4 ${ }^{+}$T-cells to pTregs (148).

\section{Functions of Intestinal Tregs}

Foxp $^{+}{ }^{+}$ATA $^{+}{ }^{+}$intestinal Tregs express high level of ST2 (108). These Tregs express high levels of tissue repair factor, an EGF like growth factor Amphiregulin $(108,149)$ (Figures 3 and 4A). It appears that Amphiregulin mediated tissue repair might be a generalized mechanism employed by tissue-resident Tregs as exemplified by its evolving role in lung resident as well as intratumoral Tregs $(150,151)$. Foxp $3^{+} \mathrm{ROR} \gamma \mathrm{t}^{+}$Tregs express increased levels of ICOS, CTLA4, and the nucleotidases CD39 and CD73 altogether, indicating robust regulatory functions $(107,129)$. Interestingly, Foxp $3^{+} \mathrm{ROR} \gamma \mathrm{t}^{+}$Tregs have been implicated in regulating both Th 2 and Th $1 /$ Th 17 mediated immunity in two independent studies, implicating animal housing conditions as an important determinant of the type of immune response $(107,129)$. siLP Foxp $3^{+} \mathrm{ROR} \mathrm{t}^{-}$Tregs primarily work toward containment of Th1 immunity. When OTII T-cells are transferred in AF mice, T-cells primarily convert to IFN $\gamma^{+}$ OTII cells and induced Tregs are mainly Tbet $^{+}$, although the extent of such ROR $\gamma \mathrm{t}^{-}$pTreg induction in AF conditions was severely compromised compared to SPF conditions (109). As a consequence, in an experimental model of food allergy, where SPF BALB/c mice were weaned onto an amino acid diet, higher diarrheal instances were reported than mice on normal chow (109). While these results underscore an important function of ROR $\gamma \mathrm{t}^{-}$pTregs in curbing food allergy, further transcriptomic and phenotypic analyses might provide additional clues to their functions.

Of note, one more function of siTregs was identified recently while looking at the IEL population. It was observed that LP Tregs migrate to epithelial compartment as well, where a fraction of them lose Foxp3 expression (152). Further, these Tregs then give up ThPOK expression leading to de-repression of $C d 8$ locus and thus, get converted into a CD $4^{+} \mathrm{CD} 8 \alpha \alpha^{+}$IELs (152) (Figure 4B). IELs have cytotoxic as well as immunoregulatory machinery suggesting a role in both mucosal barrier maintenance and elimination of stressed intestinal epithelial cells (153). 


\section{SKIN Tregs: KEEPS YOUR HAIR ON}

Skin is the largest organ amounting to almost $15 \%$ of adult human body weight. Being our exterior, it is always exposed to environmental, microbial, physical, and chemical insults. Skin also harbors more than $10^{12}$ bacteria $/ \mathrm{m}^{2}$ (154) in the surface intercorneocytic spaces.

\section{Skin Architecture}

Anatomically, skin is composed of three layers, the outer epidermis, middle dermis, and inner subcutaneous tissue layer (155). The terminally differentiated keratinocytes in epidermis synthesize long, thread-like protective protein keratin and form a physical barrier. Products of various sweat and sebaceous glands interspersed at epidermal-dermal junction along with antimicrobial peptides develop an acidic hydrophilic skin which acts as a biochemical barrier (154). The epidermal-dermal junction also hosts hair follicles. Cellular component of epidermis comprises of Langerhans cells (specialized skin DCs) and T lymphocytes. The dermis is composed of layers of thick and thin collagen fibers which provide mechanical framework to host blood vessels and various immune cells like dermal DCs, $\alpha \beta$ and $\gamma \delta$ T-cells, NK cells, B cells, macrophages, and mast cells (154). Understandably, given the exposed nature of skin, it is highly vulnerable to overzealous immune responses against skin commensals and self-antigens. Tregs are an important component of establishing tolerance and homeostasis in the skin. Indeed, both scurfy mouse and human IPEX patients present fulminating immune responses in skin. A study, examining children with IPEX syndrome reported that more than $70 \%$ children presented Atopic Dermatitis and eczema with 1.5 months as median age of onset of symptoms (156).

\section{Skin Treg Origin and Accumulation}

Normally, $30-50 \%$ and $20-30 \%$ of total CD4 ${ }^{+}$T-cells are Tregs in mouse and human skin, respectively $(157,158)$. It is difficult to establish the origin of cutaneous Tregs, given the paucity of specific information. However, a wave of Tregs has been shown to populate the skin in early neonatal period in a skin bacterial colonization model in mice (159). Furthermore, restricting lymphoid emigration of T-cells by treating with sphingosine1-phosphate receptor antagonist FTY720 resulted in preferential accumulation of Tregs in thymus instead of skin draining LNs, suggesting their migration directly from thymus (159). In humans, the cutaneous Tregs and Tconv cells share very few TCR $\beta$ sequences and these Tregs present a fully demethylated FOXP3 CNS2 region, suggestive of their stability and thymic origin $(157,160,161)$. This is little surprising as skin Tregs establish tolerance to not only self-antigens but also to commensals. How are then commensal antigen-specific Tregs generated in thymus? One possibility appears to be plasmacytoid DCs (pDCs) that have been shown to be able to take up innocuous peripheral antigens to thymus (162) and LNs (163) to induce tolerance. Generally, pDCs are not present in skin but can accumulate in the presence of inflammatory conditions $(164,165)$. Another probability is that some tTregs have TCRs with sufficient crossreactivity to microbial antigens and thus can specifically expand and accumulate at sites where antigen is present. However, if indeed skin Tregs are thymic by origin, the concerning mechanisms remain to be elucidated.

Modeling of inducible expression of a self-antigen, by fusing transferrin receptor transmembrane domain, GFP and amino acids 230-359 of chicken ovalbumin in mouse epidermis, revealed that circulating Tregs are not able to suppress primary immune response against OVA, though it initiated activation of Tregs (166). The inflammation resolved spontaneously and any subsequent antigen expression led to an attenuated and short immune response. Further analysis revealed that a fraction of Tregs persisted in the skin which expressed low level of CD25 but higher KLRG1, CTLA4, and CD127, akin to the memory T-cells (166). It is to be noted here that a recent study examining the transcriptional, epigenomic, and functional changes in inflammation experienced Tregs employing the Foxp $3^{\text {DTR }}$ system, presented that Tregs revert most of the activation induced changes and lose the accentuated suppressive ability over time (167). An earlier report revealed that cutaneous Tregs express CCR4 and adhesion molecule Integrin $\alpha \mathrm{E}, \mathrm{CD} 103$ (168). In a mixed bone marrow chimera study, CCR4-deficient Tregs could not reconstitute the skin Treg compartment (168). CCL17 and CCL22 are known chemokine ligands for CCR4 $(169,170)$, which are differentially expressed in inflamed skin mainly by endothelial cells and dermal DCs, respectively (171). These molecules sequentially manage T-cell homing to skin, where CCL17 promotes vascular recognition and extravasation and CCL22 guides subsequent migration in skin (172). More than 70\% skin Tregs express GATA3, although its deletion in Tregs does not alter Treg profile or cause overt skin related phenotype under homeostatic conditions (110).

Since skin is heavily exposed to commensals as well as pathogens, it is imperative to speculate that a fine tuning of effector and suppressive immune responses has evolved. The commensal microbiota residing within skin has been shown to calibrate barrier immunity $(173,174)$. To identify mechanisms behind development of tolerance to skin commensals, Scharschmidt et al. performed some elegant experiments with model peptide antigen expressing Staphylococcous epidermidis, a human skin commensal which efficiently colonizes mouse skin (159). Surprisingly, skin colonization in adult mice did not evoke any tolerance to bacteria, as seen by inflammatory response upon re-challenge. However, when neonatal mice were colonized for a week during postnatal week 2 , there was an appreciable attenuation of inflammatory response upon re-challenge after 3-4 weeks. Subdued response was associated with marked enrichment of antigen-specific Tregs in skin and draining LNs and the tolerance could be reversed upon FTY720 treatment (159). Another study has also shown that Tregs, generated very early in life in a defined perinatal window, play a very distinct role in maintaining selftolerance (175). Thus, in mice, an abrupt wave of Treg infiltration occurs in a defined early postnatal period to establish dominant tolerance toward skin commensals (159) (Figure 5).

Both Tregs and skin commensals are localized to hair follicles and in mouse, the time of Treg infiltration (week 2 postnatal) is coincident with hair follicle development $(176,177)$. Thus, it was speculated that hair follicles might have a role in ingress of 


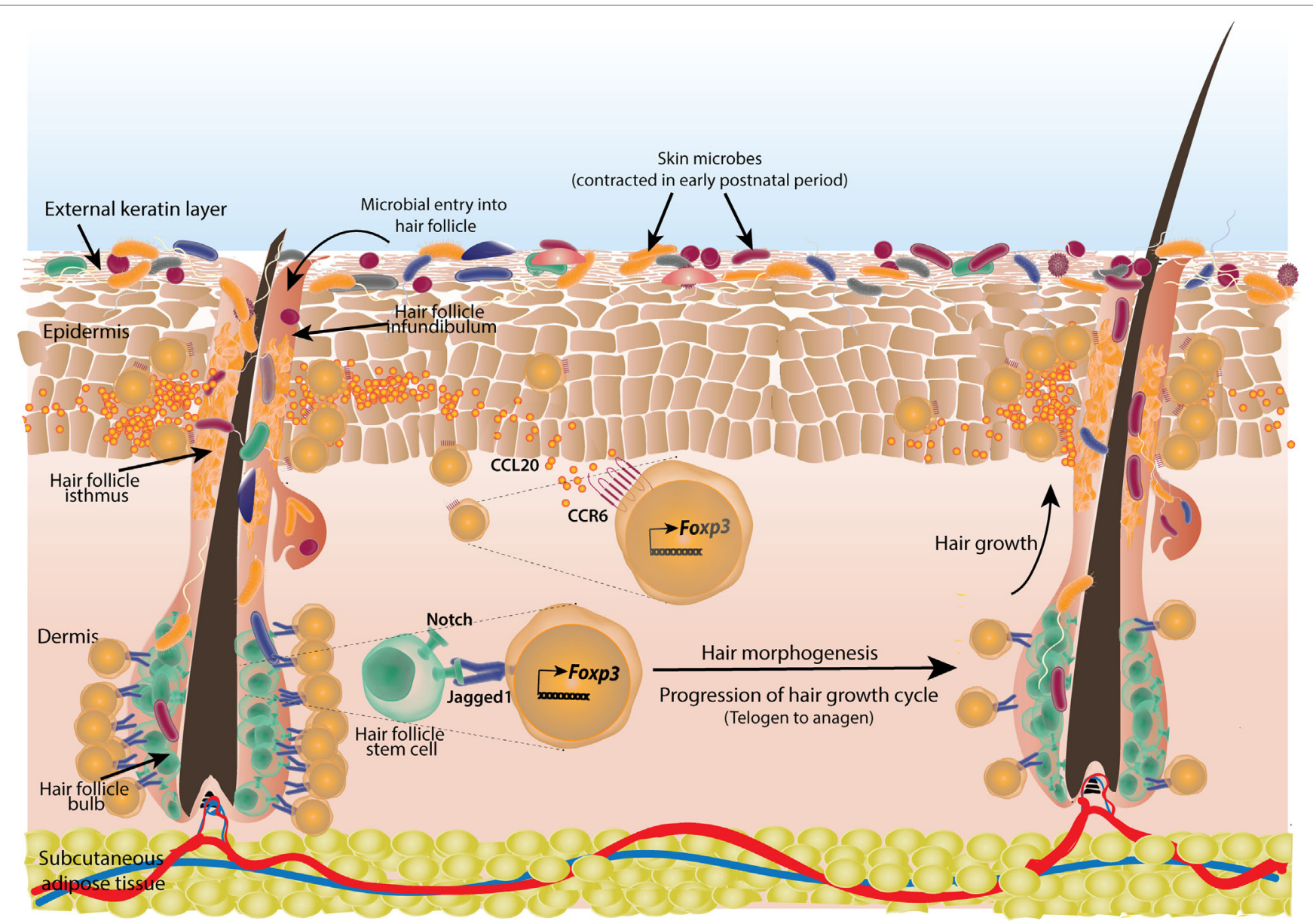

FIGURE 5 | Cutaneous regulatory T-cells (Tregs) facilitate hair morphogenesis and establish tolerance to skin commensals. Skin Tregs colonize mouse skin in early postnatal period coinciding with initial microbial colonization and hair follicle development. Skin microbes enter the hair follicle which induces production of chemokine CCL20 from infundibular cells that attracts large number of Tregs expressing corresponding receptor CCR6. The accumulated Tregs subsequently establish tolerance to these commensals. Also, during the resting phase of hair growth (telogen) which initially coincides with commensal entry in hair follicle, large number of Tregs are seen in contact with hair follicle stem cells (HFSCs) in the bulb of follicle. These Tregs provide notch ligand Jagged1 to the stem cells. Notch signaling triggers the active phase of hair growth cycle (anagen). Tregs are reduced in anagen phase around HFSCs.

Tregs in skin. It has been shown that chemokines from different parts of hair follicles like CCL2 from isthmus, CCL20 from infundibulum, and CCL8 from bulge keratinocytes generate specific type of Langerhans cells (178). Similarly, in a mouse model of skin specific hair follicle morphogenesis arrest, skin Treg population was reduced without affecting Treg population in intestine or draining LNs in neonatal mice (179). Further investigations revealed that neonatal SPF mouse skin produces high amount of chemokine CCL20 whose receptor CCR6 was found to be enriched on cutaneous Tregs (Figure 5). It was confirmed by adoptive transfer experiments that CCR6-deficient Tregs were at a competitive disadvantage to reconstitute skin T-cell compartment (179). Tregs in neonates also express high CCR8 and its ligand CCL22 is, in turn, expressed in skin. However, their contribution in establishing and/or maintenance of skin Tregs is yet to be examined. CCL20 mRNA expression also increases in human fetal skin explants upon exposure to cutaneous commensals and bacterial components (179). Thus, tissue morphogenesis (hair follicle generation and subsequent chemokine production by the cells of hair follicle) and commensals are shown to cooperate in developing a tissue-specific immune tolerance. It would be interesting to extrapolate this model to other microbe inhabited organ systems. Whether, these mechanisms sustain throughout the life span particularly in adult life is not known. Earlier, 8- to 12-week-old GF mice were reported to have about twofold more cutaneous Tregs than SPF animals (180). It is possible that yet unknown factors other than commensals increase Treg population in adult GF skin or a lack of tuned immune response against commensals diverts immune resources toward self-antigens and in turn, progressively enrich self-antigen-specific Tregs in skin.

Short wavelength Ultraviolet (UVB) exposure also enriches and accumulates Tregs in mouse skin (181). UVB exposure damages self-RNA in keratinocytes which is sensed by TLR3 to generate an inflammatory response (182). Indeed, the Tregs accumulating post-UVB exposure were $\mathrm{Nrpl}^{+}$with highly demethylated Foxp3 CNS2 (181). These Tregs highly expressed 
homing molecules like CD103, CCR4, and P-lig and thus, were able to migrate to the non-UVB exposed parts of the skin as well (181) (Figure 6). Interestingly, UVB phototherapy is an effective treatment in autoimmune skin conditions, like psoriasis (183) and atopic dermatitis (184).

\section{Tissue Adaptations and Homeostatic Functions}

True to the nature of tissue-resident Tregs where they have been shown to not only develop immune tolerance but also get accustomed to and help local physiology, cutaneous Tregs in hair follicles have been found to modulate hair follicle stem cells (HFSCs) in addition to establishing tolerance to commensals. In mouse skin, an abundance of Tregs was found during telogen phase of hair follicle growth which is characterized by quiescence only to be followed by an active proliferation phase called anagen. Treg population decreases during anagen phase. And as these phases alternate in mouse skin so are the numbers of hair follicle associated Tregs (158) (Figure 5). Animals with transient depletion of Tregs during telogen, failed to progress to anagen phase and could not re-grow hairs (158). It was not inflammation related, as transient depletion of Tregs did not elicit any major inflammatory event in skin and co-depletion of either effector $\mathrm{CD}^{+}, \mathrm{CD}^{+}, \mathrm{Gr}-1$ expressing neutrophils or $\mathrm{CD} 11 \mathrm{C}^{+}$myeloid cells did not rescue HFSC proliferation (158). This suggested a non-immune role of Tregs in HFSC proliferation. Akin to Tregs in hematopoietic system which form an immune-privileged site to provide a protective niche to hematopoietic stem cells (185), hair follicle Tregs were found to co-localize with HFSCs. These Tregs highly express "jagged 1" which encodes a ligand for notch signaling pathway responsible for HFSC proliferation (158) (Figure 5).

Regulatory T-cells play an important role in cutaneous wound healing as well. They accumulate in large numbers at the site soon after a wound injury in skin (186). These Tregs are of activated

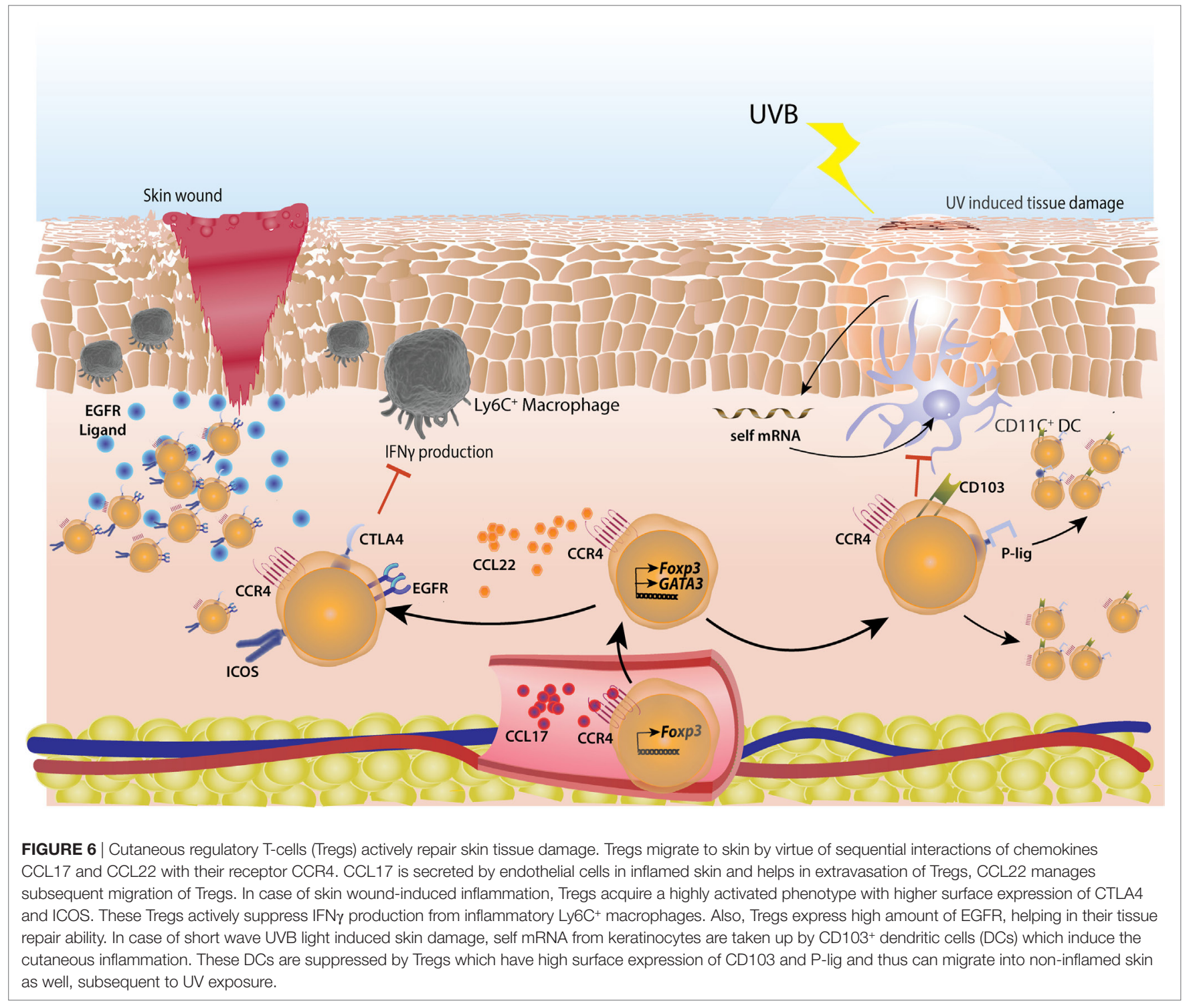


phenotype with high CD25, CTLA4, and ICOS expression and limit the IFN $\gamma$ producing T-cells and inflammatory macrophages in wounds (186). The Tregs involved in cutaneous wound healing were shown to be dependent on EGFR pathway (186) as in lung and muscle-healing Tregs (150, 187, 188) (Figure 6).

\section{TUMOR-INFILTRATING REGULATORY T-CELLS (TI-Tregs): A BATTLE WON, WAR LOST}

Tumors are wounds that do not heal (189-191). Solid tumors, in particular, heterogeneously indulge in various stages of wound healing, which provide essential growth factors for the tumor growth. This hijack of natural processes results in heightened inflammation and its subsequent resolution in the tumor microenvironment, presumably setting up a vicious cycle. Inflammation on one hand provides growth and metastasis opportunities; resolution of inflammation helps the tumor to escape antitumor immunity. Therefore, it is not surprising that many solid tumors including hepatocellular (192), gastric (193), lung (194), breast (195), ovarian (196), cervical (197), and melanomas (198) summon comparatively large numbers of Tregs which sometimes account for even more than $50 \%$ of $\mathrm{CD}^{+}$T-cell compartment (199). For most of the tumors, the presence of high number of Tregs indicates a guarded to grave prognosis. However, several studies reported a favorable role of FOXP3 $^{+}$T-cells in colorectal carcinomas (CRC) (200-202). It is to be noted that FOXP3 expression is not exclusive to bona fide Tregs in humans, often, effector T-cells express FOXP3, albeit transiently $(203,204)$. Based on expression levels of FOXP3 and Protein tyrosine phosphatase isoform A (CD45RA), human peripheral blood $\mathrm{FOXP}^{+} \mathrm{CD}^{+}{ }^{+} \mathrm{T}$-cells can be classified into FOXP $3{ }^{\text {hi }} \mathrm{CD} 45 \mathrm{RA}^{-}$bona fide Tregs which are highly suppressive and phenotypically eTregs; FOXP $3{ }^{\text {lo }} \mathrm{CD} 45 \mathrm{RA}^{+}$naïve T-cells and FOXP $3{ }^{\text {lo }} \mathrm{CD} 45 \mathrm{RA}^{-}$effector T-cells which are not suppressive in an in vitro suppression assay (203). Indeed, careful analysis of TILs in human CRC by Saito et al. (205) revealed the heterogeneity of FOXP3 expression. The authors identified that CRC, where higher expression of FOXP3 was associated with favorable outcomes, were actually infiltrated more with FOXP $3{ }^{10} \mathrm{CD} 45 \mathrm{RA}^{+}$ effector T-cells and upregulated inflammatory genes like Il12a, Il12b, Tgfb1, and Tnf. Higher infiltration of FOXP3 ${ }^{\text {hi }} \mathrm{CD}_{45 \mathrm{RA}^{-}}$ cells resulted in poor prognosis and lower disease-free survival (205) as reported for other tumors.

\section{Origin and Accumulation of TI-Tregs}

As tTregs and pTregs differ in their stability, conclusive information about origin of TI-Tregs can be very valuable to design TI-Treg specific therapies in cancers. Tumors drive immune responses against tumor-associated self-antigens as well as tumor-specific neo-self antigens. Thus, in theory, Tregs against self-antigens (tTregs) and pTregs against neo-self antigens are possible. Presence of high levels of TGF $\beta$ in most solid tumors reinforces the idea of generation of pTregs in tumor microenvironments $(206,207)$. However, TI-Tregs in several murine tumors have been shown to express high levels of Nrp1 and
Helios proteins, suggestive of a thymic origin (208). Attempts for in situ conversion of conventional $\mathrm{CD} 4^{+} \mathrm{T}$-cells to Tregs against tumors expressing model antigens did result in intratumoral pTregs generation $(209,210)$, but monoclonal populations of antigen-specific T-cells do not recapitulate physiological conditions where antigen-specific T-cells represent less than $5 \%$ of TILs (211-213). TCR repertoire analyses have revealed almost no overlap in Foxp3 ${ }^{+}$and Foxp3 ${ }^{-}$T-cells in autochthonous prostate tumors (214), carcinogen-induced tumors (215), and in heterotopic transplanted tumors in mice (216). Further, these studies confirmed that there is enrichment and expansion of selective TCR bearing Tregs inside tumor microenvironment $(214,216)$. In human breast cancers $(217)$ and hepatitis B virus positive hepatocellular carcinomas (HCC) (192), very low TCR repertoire overlap between TI-Tregs and conventional T-cells suggests little to no conversion of conventional CD $4^{+} \mathrm{T}$-cells into Tregs (Figure 7A). Malchow et al. (214) developed a transgenic mouse expressing the model oncogene SV40 T antigen in prostate

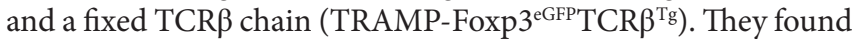
that Tregs expressing a single TCR (MJ23), reactive to a normally expressed prostate antigen, consistently populated the tumors (214). This TCR was able to drive a tTreg clone development. However, a deficiency of the transcription factor autoimmune regulator abolished development of these clones (214), suggesting that at least in these experimental settings, TI-Tregs are generated in thymus against a normal tissue expressed self-antigen (Figure 7A). Recently, two MHCII restricted natural self-antigen ligands of MJ23 Tregs were discovered. Both of these ligands are non-overlapping peptides originating from same prostatic protein (Tcaf3) and while one is expressed in mouse prostate tumors (MJ23), the other is associated with prostatic autoimmune lesions (SP33) (218). Another study focusing on epigenetic hallmarks of tTregs found that TI-Tregs had consistently hypomethylated Foxp3 CNS2 in various orthotopic and heterotopic transplanted tumor models, even at different time points of tumor growth (219). These findings were further confirmed in TI-Tregs from different human tumors. It is to be noted that there have been equivocal reports about the demethylated CNS2 being specific for tTregs, since Foxp3 CNS2 region in pTregs has also been shown to be demethylated $(220,221)$, most likely upon eventual stabilization following its de novo induction.

Overall, available evidences largely point toward higher enrichment and expansion of tTregs inside solid tumors. However, why should not higher TGF $\beta$ levels and an activating tumor environment drive pTreg generation and expansion is a baffling question. Probably more conclusive lineage tracing experiments across tumors can be proven more insightful.

\section{TI-Tregs Add Another Layer of Diversification}

Recent studies analyzing transcriptome of TI-Tregs from human cancers have identified that though TI-Tregs are largely similar to normal tissue-resident Tregs, these have some specific characteristics and molecular patterns which can be utilized for selective therapy $(192,217,222)$. Plitas et al. (217) found that breast cancers, with rather aggressive phenotype, were enriched 

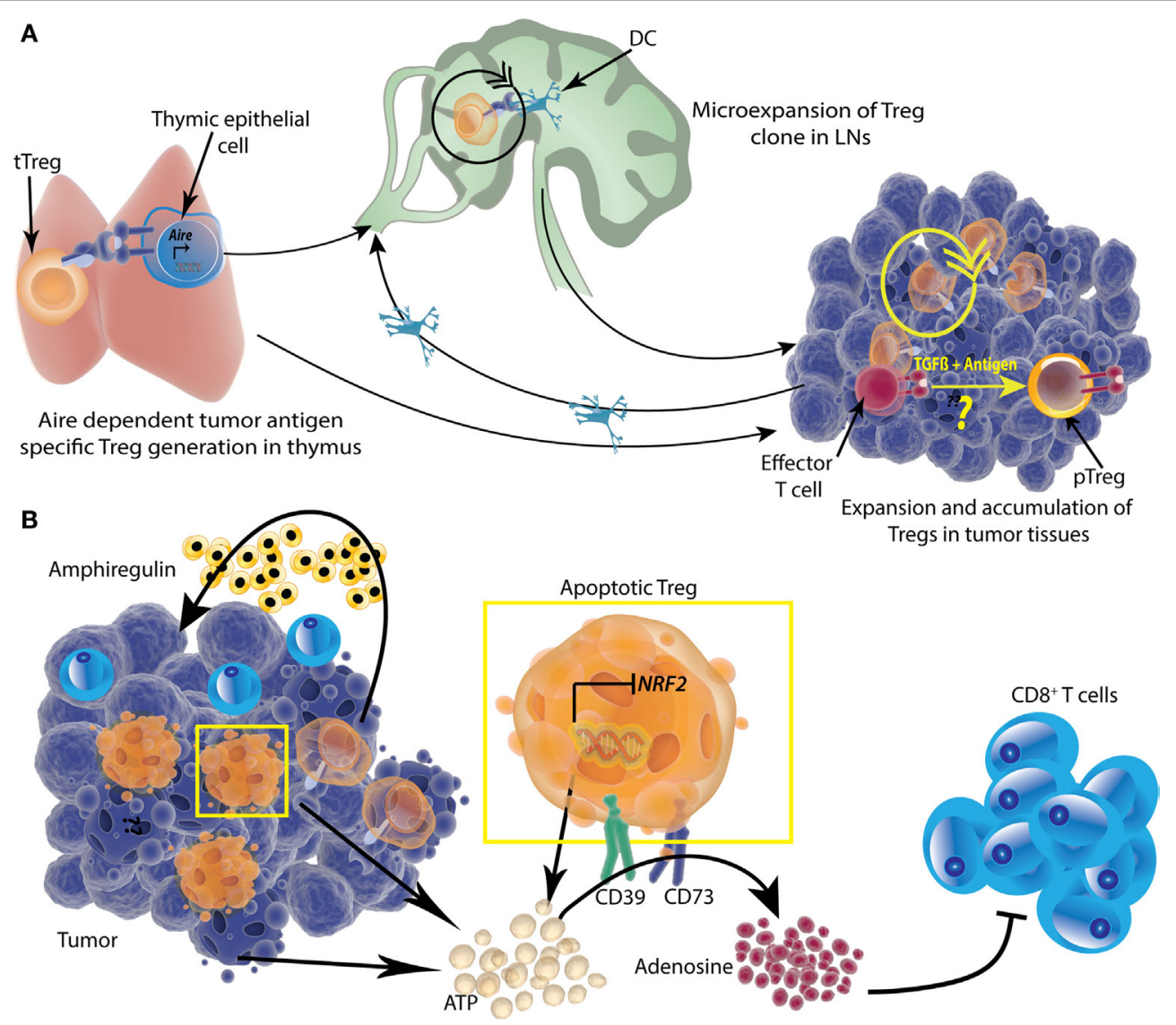

C

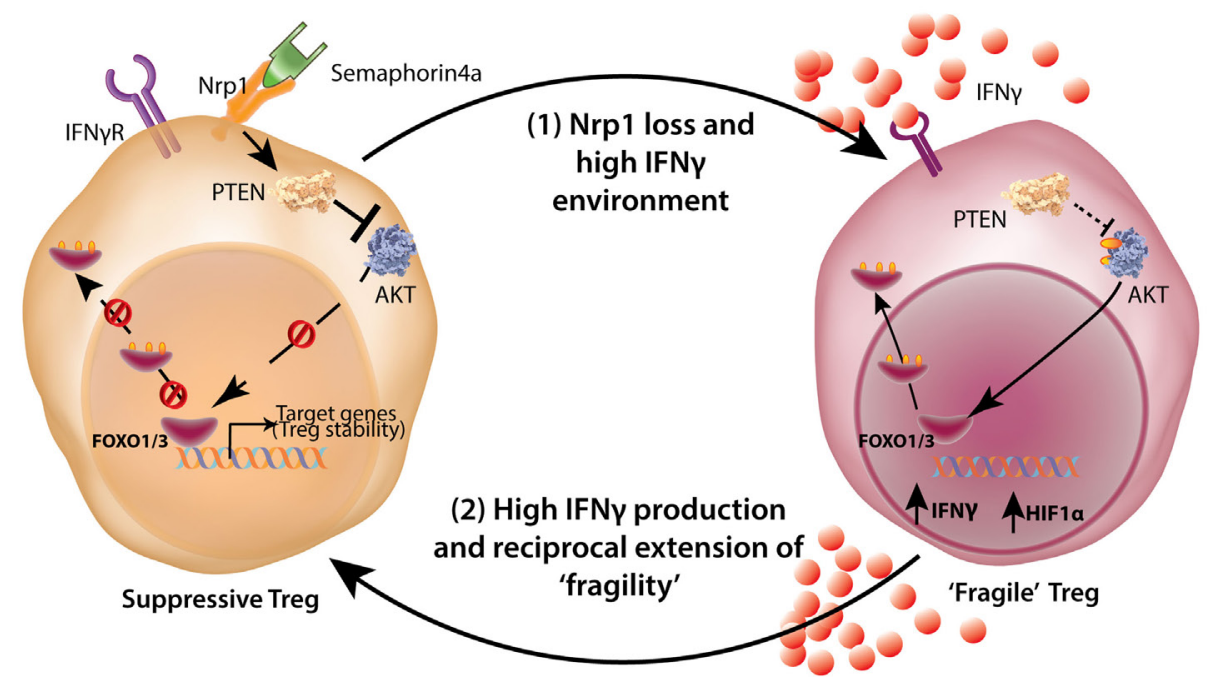

FIGURE 7 | Origin, accumulation, and functional potentiation of tumor-infiltrating regulatory T-cells (Tregs). (A) Tumor-specific antigens can be expressed by thymic epithelial cells in an Aire-dependent manner, which then select the tumor antigen-specific Tregs. These Tregs then expand in tumor draining lymph nodes (LNs) with the help of dendritic cells (DCs). Tregs can also be directly recruited to tumors and undergo expansion there. While intratumoral conversion of effector T-cells to pTregs is likely, the extent to which this occurs under physiological conditions is not completely understood. (B) A high number of TI-Tregs are apoptotic because of suppressed expression of Nrf2. These Tregs as well as dying tumor cells release copious amounts of ATP, which is converted to adenosine by Treg ectoenzymes CD39 and CD73 in a sequential manner. The resulting adenosine is highly suppressive to tumor-infiltrating CD8 ${ }^{+}$effector T-cells. Further, Tregs also produce Amphiregulin in certain tumor types, which help in tumor progression. (C) More than 50\% of TI-Tregs express surface Neuropilin1 (Nrp1), which is a receptor for Semaphorin 4a. Upon ligation with Semaphorin4a, Nrp1 activates lipid phosphatase Phosphatase and tensin homolog (PTEN) which promptly dephosphorylates AKT rendering its sequestration in cytosol and nuclear retention of Foxo1/3 transcription factors which help in stabilization and survival of Tregs. A loss of Nrp1 renders Treg highly susceptible to IFN $\gamma$ and such Tregs also produce high amount of IFN $\gamma$ and HIF1 $\alpha$ ("Fragile" Tregs). The resultant high IFN $\gamma$ environment, reciprocally, can induce "fragility" in other Nrp1-sufficient Tregs as well, setting up a vicious cycle. 
for Tregs, which were highly suppressive in a microsuppression assay and were highly proliferative based on increased expression of nuclear protein Ki67, a cellular marker for proliferation (223). Further transcriptome analysis of TI-Tregs from breast cancers and gastric cancers as well as brain metastases of NSCLC and liver metastasis of CRC, suggested a signature gene set for these cells (222). TI-Tregs expressed BATF, CCR8, CD30, IL1R2, IL21R, PDL1, and PDL2 along with FOXP3 and IL2Ra at a very high level (222). Recently, BATF was shown to be involved in context dependent gene set expression in tissue Tregs (224). In the IPEX patients, a gain-of-function mutation in FOXP3 locus (A384T) results in expanded DNA binding specificities of FOXP3. Its altered binding to BATF locus repressed BATF expression leading to repressed GATA3, ST2, and CCR4 expression in Tregs (224). These genes are significant in converting cTregs to eTregs, therefore, their decreased expression led to a widespread tissuespecific autoimmunity (224).

Genome-wide transcriptome analyses identified MAGEH1, Melanoma antigen family $\mathrm{H} 1$ gene, encoding a putative E3 ubiquitin ligase potentially regulating TI-Treg survival and function; Chemokine (C-C motif) receptor 8 (CCR8), known receptor for chemokines CCL1 (225), CCL8 (226), CCL16 (227), and CCL18 (228) in humans; CD177, a glycosyl-phosphatidylinositol-linked cell surface glycoprotein that can bind platelet endothelial cell adhesion molecule- 1 and is known for neutrophil transmigration and survival (229); and $L A Y N$, encoding a novel c-type lectin surface receptor layilin, a proposed receptor for Hyaluronan (230). However, subsequently, layilin has been found highly expressed on tumor-infiltrating cytotoxic CD ${ }^{+}$T-cells as well, particularly those with an exhaustive (highly expressing CTLA4, PDCD1, and HAVCR2) phenotype (192). Enrichment of LAYN, $M A G E H 1$, and CCR8 in whole tumor samples correlated significantly with reduced 5-year survival rate of CRC and NSCLC patients (222). CCR8 expression was exclusively enriched on TI-Tregs, whereas CCR2, CCR4, and CCR5 expressions were found on other tumor-infiltrating and/or peripheral blood Tconv cells as well. Indeed, a CCR4 depleting antibody has been shown to deplete both Tregs and Tconv cells (231). Some Tregs in draining LNs also expressed high CCR8 which might be ones earmarked for tumor infiltration or Tregs in micrometastases inside LNs (217). As peripheral blood and/or LN Tregs do not express CCR8, its importance in recruitment of Tregs to tumors is not appreciated. It is possible that CCR8 is expressed to retain Tregs in tumors. Indeed, CCR8 ligands like CCL1 and CCL18 are highly transcribed in tumor-infiltrating myeloid cells (217). Whether, CCR8 expression is an indicator of highly suppressive TI-Tregs or it has further functional importance is not yet known. However, human Tregs exposed to CCR8 ligand CCL1 and not CCL8, CCL16, or CCL18 induce surface CCR8 expression via a STAT3-mediated pathway (232). Such cells, subsequently, upregulate their expression of FOXP3, CD39, Granzyme B, and IL10 and are functionally more suppressive in a microsuppression assay and in a mouse model of multiple sclerosis (232).

\section{Function of TI-Tregs}

There is a repertoire of known and yet unknown mechanisms which Tregs utilize to suppress an immune response. TI-Tregs also use similar mechanisms which include production of immunosuppressive cytokines like IL10 and $\operatorname{TGF} \beta(233,234)$; sequestration of IL2 (235); direct cytolysis of target lymphocytes using granzyme B and perforin (236); contact based immunosuppression using surface inhibitory molecules like CTLA4 (237), PD1 (238, 239), LAG3 (240), TIM3 (241), and CD39/CD73-generated adenosine-mediated T-cell suppression via adenosine receptor 2A $(242,243)$. However, how the TI-Tregs have highly accentuated suppressive response is not very well understood. A large accumulation of Tregs might help in a collective exaggerated suppression, but it cannot explain individual potentiation. Recently, it was shown that TI-Tregs are highly apoptotic on account of comparatively low expression of the transcription factor Nuclear factor like 2 (NRF2) (244). NRF2 regulates antioxidant defense system in macrophages and epithelial cells (245). A lack of NRF2 makes TI-Tregs more apoptotic in high oxidative stress tumor microenvironment. But, owing to increased release of ATP and high CD73/CD39 expression, apoptotic TI-Tregs generate large amount of adenosine and thus, become even more suppressive (244) (Figure 7B). It is to be noted though that earlier Imatinib induced apoptosis of TI-Tregs was shown to enhance antitumor immunity (246).

TI-Tregs in human breast cancers (217) and HCC (192) highly express Il1r 2 gene encoding a decoy IL1 receptor. Also, TI-Tregs are found to be highly stable owing to the enhanced expression of lipid phosphatase Phosphatase and tensin homolog (PTEN) and VEGF receptor Nrp1 $(199,238,247)$. Binding of Nrp1 to its ligand Semaphorin4a increased Foxo1 and Foxo3 nuclear localization by inhibiting AKT phosphorylation which stabilized Treg signature genes and antiapoptotic genes (247) (Figure 7C). AKT dephosphorylation was achieved by activation of PTEN by Nrp1. Indeed, mice with Treg specific PTEN deletion generate an accentuated antitumor immune response (238). Nrp1 expression is primarily important for TI-Tregs as the loss of Nrp1 even from a fraction of Tregs under appropriate experimental conditions, rendered all the Tregs (including those that were Nrp1 sufficient) "fragile" (199). This observation emphasizes that Tregs can not only modulate other immune cells but can phenotypically influence other Tregs as well. The TI-Treg fragility was shown to be induced by IFN $\gamma$ production by Nrp1-deficient Tregs and exogenous IFN $\gamma$ (199) (Figure 7C). The authors further show that HIF1 $\alpha$ was a major factor induced in Nrp1-deficient and fragile Tregs, and both HIF $1 \alpha$ and IFN $\gamma$ can be induced by hypoxia (199). However, as most of the solid tumors become progressively hypoxic $(248,249)$, whether this phenomenon is prevalent in progressive tumors and if so, whether it is efficient for a significant regeneration of antitumor immune response, remains to be seen. TI-Tregs have been shown to highly express receptor activator of nuclear factor $\kappa \mathrm{B}$ ligand (RANKL), which upon binding to its receptor RANK expressed in mammary carcinoma cells increases lung metastasis (250). RANKL has also been implicated in renewal of breast cancer progenitor cells (251) and metastasis of prostate cancers (252) by modulating protein kinase inhibitor of nuclear factor $\kappa \mathrm{B}$ kinase $\alpha(\mathrm{IKK} \alpha)$. Overall, these findings suggest that there is a specific phenotypic and functional identity to TI-Tregs and thus, it is possible to selectively target them for triggering efficient antitumor immunity. 


\section{OTHER Tregs IN TISSUE INFLAMMATION AND HOMEOSTASIS}

As the diversity in characteristics and functions of tissue Tregs is being unraveled, several other interesting populations have been described which deserve more detailed phenotypic and functional characterization.

\section{Regeneration Powerhouse}

It was reported earlier that in a non-inflammatory model of regenerative alveologenesis, Tregs enhanced epithelial proliferation.
A Treg coculture with type II alveolar cells (AT2) increased their proliferation in CD103-dependent manner (253). In accordance to these findings, a distinct population of Tregs expressing high levels of pro-inflammatory cytokine IL18 receptor (IL18R) and ST2 has been described in lungs (150). IL18R ${ }^{+}$Tregs expand early in the course of a lung injury and enhance tissue repair by producing a large amounts of tissue repair protein amphiregulin in an "innate" manner, independent of TCR engagement (150) (Figure 8A). In animals with Treg specific amphiregulin deficiency, a rapid decline in lung functions was observed upon intranasal influenza virus infection, while antiviral immune
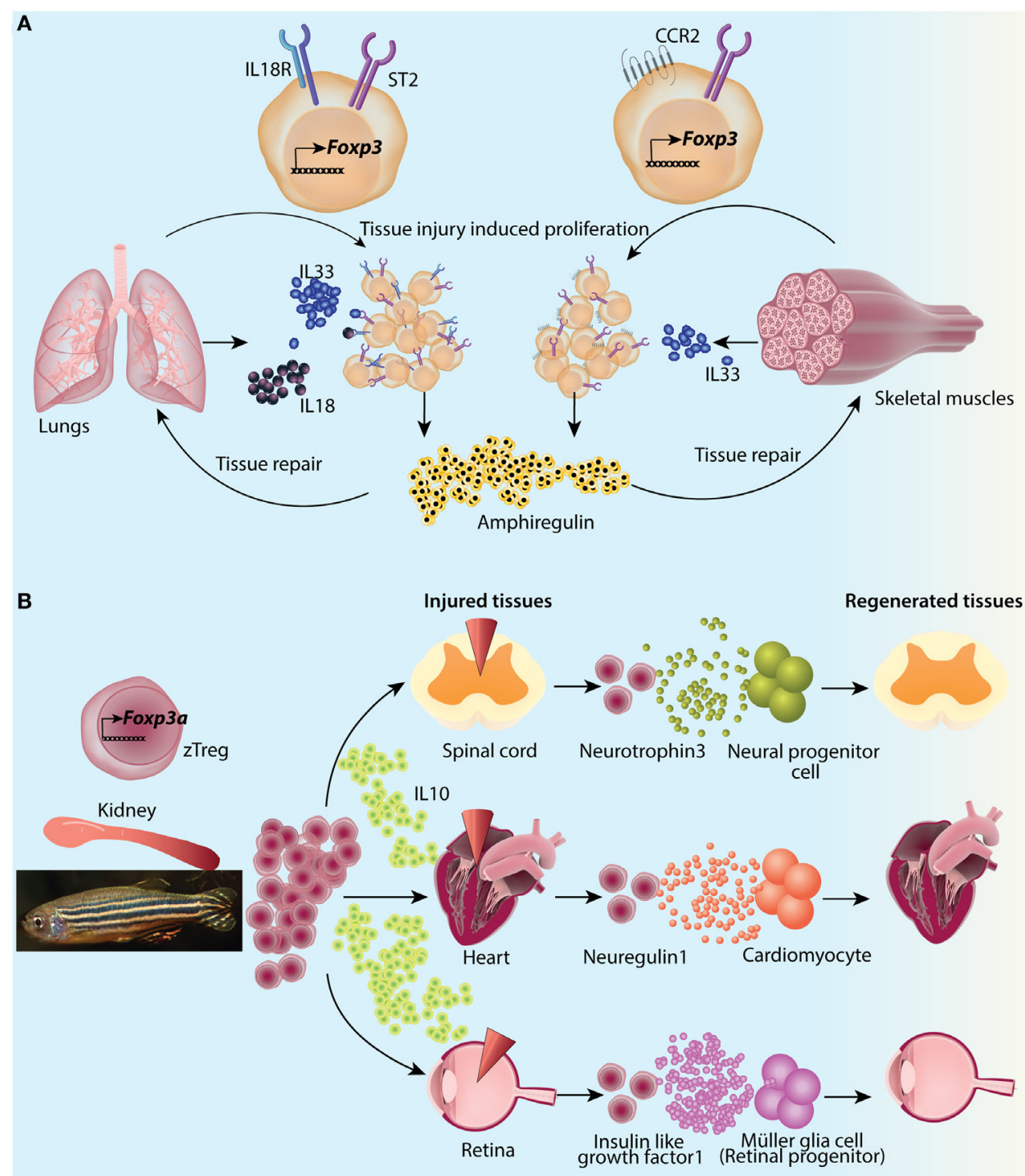

FIGURE 8 | Emerging evidences highlight a compulsory requirement of regulatory T-cells (Tregs) in tissue regeneration and repair. (A) Both lungs and muscles contain population of Tregs which proliferate vigorously upon tissue injury. Lung reparative Tregs respond to both inflammatory IL18 and alarmin IL33 and produce amphiregulin in a TCR-independent manner. Muscle Tregs respond to IL33 produced upon muscle damage and produce amphiregulin for subsequent repair. (B) In zebrafish, mammalian Foxp3 ortholog Foxp3a expressing Tregs (zTregs) are primarily present in kidney. However, upon tissue injury, they soon accumulate at the site of the injury. Apart from anti-inflammatory IL10 production, zTregs co-localize with organ progenitor cells and provide tissue-specific growth factors to progenitors like neurotrophin3 for neural progenitors in spinal cord, neuregulin1 for cardiomyocytes in heart, and insulin-like growth factor1 to Müller glial cells in retina. 
response was intact (150). Transcriptomic analysis revealed that these "repair Tregs" have a distinct gene expression pattern indicating their proficiency in extracellular matrix remodeling and tissue repair (150).

Another unique tissue Treg population has been found in skeletal muscles, where by virtue of amphiregulin secretion, they help in muscle regeneration and healing. These cells, usually accounting for $10 \%$ of muscle T-cells at a steady state, proliferate vigorously after an intramuscular administration of cardiotoxin, which induces hypercontraction and myofibril death induced acute injury (254), reaching close to $50 \%$ of muscle T-cell population (188). High expression of Nrp1 and Helios and a unique and restricted TCR repertoire suggests thymic origin of muscle Tregs and reactivity to a local muscle antigen (188). These Tregs have a unique transcriptome compared to lymphoid organ Tregs with several differentially expressed genes. They have upregulated transcripts involved in Treg mediated suppression (Il10, Gzmb, etc.), tissue repair (Il1rl1, Areg, etc.), and muscle regeneration (255) (Ccr2) as well as genes encoding proteins found in contractile muscle function (256) like nebulin and nebulin-like proteins (Neb, Nebl). Depletion of Tregs during a muscle injury episode delays muscle healing, most probably because of loss of Treg generated amphiregulin. Also, fibro/ adipogenic progenitors in skeletal muscles produce high levels of IL33, whose receptor ST2 is highly expressed on muscle Tregs. Thus, muscle Tregs seem to be involved in an alarmin induced repair process (Figure 8A). Interestingly, muscle Treg population declines in old age mice which results in a deterioration of repair and regeneration process (257).

Recently, a very elegant and detailed (258) study in zebrafish has elaborated upon yet unknown and spectacular regenerative capabilities of Tregs (Figure 8B). The authors found that an ortholog of mammalian Foxp3, Foxp3a, which was exclusively expressed in a subpopulation of zebrafish T-cells, was upregulated most prominently in distinct regenerating organs. Zebra fish Tregs (zTregs) were predominantly found in kidneys but infiltrated and vigorously proliferated in regenerating tissues. As in the mammalian counterparts, these cells expressed high levels of Nrp1a and Helios in comparison to kidney zTregs (258). It has been reported that CNS1 region of Foxp3 locus, responsible for pTreg generation, is not found in zebrafish (259). For identification of zTreg's role in organ regeneration, punctual and continuous deletion of Foxp $3 a$ resulted in reduced and delayed regeneration in heart, spinal cord, and retina injury models (258). Deletion of zTregs, in fact, reduced the tissue-specific precursor cells and subdued their proliferation (258). Indeed, zTregs were found near progenitors, sometimes even in close contact (258). However, the most striking finding of this study is that zTregs which presumably came from a common unbiased pool, became plastic in a tissue-specific regenerative context and produced tissue precursor cell specific regeneration factors like Neurotrophin 3 for neural progenitors in regenerating spinal cord, Neuregulin 1 for cardiomyocytes in injured heart and insulin-like growth factor 1 for retinal progenitor Müller glia cells (258) (Figure 8B). That zTregs are the primary source of these growth factors was confirmed by rescue of regeneration in zTreg depleted tissues by recombinant tissue-specific growth factors (258). The regeneration potential of zTregs was independent of their immunosuppressive potential or at least was not dependent on their IL10 production as IL10-deficient cells were fully capable of inducing precursor cell proliferation. However, regeneration potential was Foxp3a-dependent as regeneration process was significantly reduced in Foxp $3 a^{-/-}$tissues along with growth factor expression levels (258). On the other hand, Areg expression was not Foxp $3 a$ dependent and its role in regeneration was limited. It would be interesting to extrapolate and confirm similar findings in murine and human tissues.

\section{Feto-Maternal Tolerance}

An equally fascinating population of Tregs which accumulates in murine placenta to induce maternal tolerance to fetus has been described (259). To say that the Tregs are extremely important from the outset of pregnancy will not be an overshoot [reviewed in Ref. $(260,261)]$. Indeed, mating itself expands uterine Tregs and induces a transient "tolerance" to paternal alloantigens (260). In both humans and mice, seminal plasma contains TGF $\beta$ and prostaglandin E, which are potent Treg inducers. In fact, seminal fluid in humans and rodents contains highest measured TGF $\beta$ levels among biological fluids (260). Women with recurrent spontaneous abortions have reduced Treg population (262). Female decidual and uterus draining LN Treg generation is CNS1 dependent (259) and increased fetal resorption and placental T-cell infiltration was observed in CNS1-deficient mice. Apart from the their most likely peripheral origin, it is not known whether these Tregs have a distinct phenotypic and functional profile, elucidation of which could come very informative toward amelioration of infertility, pre-eclampsia, and other spontaneous abortive disorders. Very recently, an elegant study on human fetal antigen presenting cells (263) has found that fetal counterparts of DCs are primarily tolerogenic in their response. And, the primary response is generation of Tregs, even more than the adult DCs, in an in vitro Treg differentiation assay (263). These DCs were found across several fetal tissues, including spleen, thymus, skin, gut, and lungs (263). Unfortunately, the authors did not describe if Tregs were also present in these tissues. Earlier, it has been shown that human fetal Tregs promote tolerance to non-inherited maternal antigens (264) but only recently, it came to light that Tregs are required for suppression of in utero autoimmunity as well. Two children with IPEX syndrome, who died soon after birth, presented histological evidences of tertiary lymphoid structures, chronic inflammatory changes, and targeted exocrine pancreas autoimmunity (265). This signifies that in the perplexing settings of a pregnancy, Tregs are instrumental in establishing tolerance at both ends of maternal-fetal relationship.

\section{CONCLUSION AND PERSPECTIVES}

Translational utility of many biological processes is marred by lack of specificity. A similar dilemma exists for Treg biologists as well; however, in case of Tregs selective therapeutic targeting appears to be achievable by virtue of harnessing their gradually established phenotypic and functional diversity. Recent studies have provided evidence that even for the organs like testes and 
eye, which are conventionally considered immune-privileged; there are populations of Tregs maintaining dominant tolerance and/or tissue homeostasis. While in testis, where otherwise privileged autoantigen escapes from the seminiferous tubules, only to generate systemic tolerance via Tregs (266), the retina actively recruits Tregs, which not only attenuate inflammation, but also repair the vasculature, saving blinding neovascular retinopathies (267). Another layer of specificity is added by discovery of tissueresident Tregs and their unique characteristics. However, most of the information except the recent reports on skin resident Tregs and TI-Tregs are from mouse tissues. There are several differences in structure as well as physiology between mice and humans. For example, mouse skin contains a thin muscle layer panniculus carnosus, which is vestigial in humans (268). This helps in contraction, revascularization and healing of wounds without scar formation in mouse. Human skin on the other hand heals by secondary intention leaving scar tissues. Thus, it is important to identify human tissue Tregs for an informed effort toward therapeutic usage.

There is a need to conclusively establish the origin and accumulating factors for tissue Tregs. One of the most pressing questions about almost all the tissue Tregs is identification of their natural ligands or tissue antigens. Although it has been demonstrated that in certain cases Tregs do not need TCR stimulation for some of their functions (150), Tregs with a smaller subset of specific TCR repertoire populate various tissues as well as malignancies. Therefore, cognate ligands that help in survival and proliferation of Tregs in these tissues are likely to have significant contributions in catering tissue-specific modulations. Proof of concept studies provide evidence that Tregs with defined antigen specificity (chimeric antigen receptor Tregs, CAR-Tregs) have potent immunosuppressive functions along with advantage of not inducing generalized immunosuppression (269).

Question remains as to how Tregs communicate with specific tissue cells-like adipocytes to establish a channel of communication with the environment. Beyond adaptation to inflammatory context, there are peculiarities of Treg biology, which modulate their effect temporally in life as well. Such as, Treg accumulation in aging WAT induces insulin resistance (79), whereas its accumulation in young obese WAT ameliorates it (83). The mechanisms that drive such specific outcomes need to be studied in detail. This accentuated capability to adapt sometimes becomes counterproductive too as seen in tumors where the suppressive capacity is enhanced even in comparison to normal tissue-resident Tregs and is, in turn, utilized by tumors for their

\section{REFERENCES}

1. Golub ES, Green DR. Immunology. Sunderland, MA: Sinauer Associates (1991).

2. Grignolio A, Mishto M, Faria AM, Garagnani P, Franceschi C, Tieri P. Towards a liquid self: how time, geography, and life experiences reshape the biological identity. Front Immunol (2014) 5:153. doi:10.3389/fimmu.2014.00153

3. Luo X, Miller SD, Shea LD. Immune tolerance for autoimmune disease and cell transplantation. Annu Rev Biomed Eng (2016) 18:181-205. doi:10.1146/ annurev-bioeng-110315-020137

4. Steinman RM. Decisions about dendritic cells: past, present, and future. Annu RevImmunol (2012) 30:1-22. doi:10.1146/annurev-immunol-100311-102839 survival and immune escape. The mechanisms by which Tregs can push the limits of their functional capabilities are yet to be identified.

A major aspect of tissue adaptation is adjusting the cellular metabolism according to the tissue environment. There are huge gaps in our understanding of both lymphoid and tissue Treg metabolism. In in vitro differentiated Tregs (iTregs), it was shown that Foxp3 suppresses glycolysis by repression of Myc and helps in developing resistance to L-lactate (270). Similarly, Foxp 3 counters PI(3)K-Akt-mTORC1 to diminish glycolysis in iTregs (271). Contrastingly, splenic and TI-Tregs were shown to uptake more 2NBDG, a fluorescent glucose analog, while intratumoral effector $\mathrm{T}$ cells showed glucose deprivation leading to reduced production of glycolytic metabolite phosphoenol pyruvate, resulting in compromised effector functions via reduced calcium-NFAT signaling (272). More recently, glycolysis was found to be instrumental in Treg trafficking and migration to inflamed tissues. The induction of the glycolytic enzyme glucokinase GCK and cytoskeletal rearrangement upon its association with actin was shown to be critical for the process (273). These findings underscore the need for extensive studies to delineate metabolic reprogramming in not only tissue Tregs but also lymphoid Tregs under steady state and activated conditions.

One can only be amazed by the diversity and functional plasticity of Tregs. A question, therefore, always comes up as to why Tregs are the chosen ones? Whether similar diversities among other immune cell types are still awaiting discoveries, or whether Foxp3 and presumably other unknown factors provide some degree of functional uniqueness to Tregs, remains to be seen. Nevertheless, looking at the diversity of responses ranging from maintaining immune tolerance to tissue repair, to becoming a major stakeholder in maintenance of physiological function of tissues, it would be apt to say that Tregs are the proverbial "Jack of all trades," and certainly, "master" of some.

\section{AUTHOR CONTRIBUTIONS}

AS and DR planned and wrote the manuscript.

\section{FUNDING}

This work was supported by Project IBS-R005 of the Institute for Basic Science, Korean Ministry of Science, Information/ Communication Technology and Future Planning.

5. Lewis KL, Reizis B. Dendritic cells: arbiters of immunity and immunological tolerance. Cold Spring Harb Perspect Biol (2012) 4(8):a007401. doi:10.1101/ cshperspect.a007401

6. Liu J, Cao X. Regulatory dendritic cells in autoimmunity: a comprehensive review. J Autoimmun (2015) 63:1-12. doi:10.1016/j.jaut.2015.07.011

7. Mauri C, Menon M. Human regulatory B cells in health and disease: therapeutic potential. J Clin Invest (2017) 127(3):772-9. doi:10.1172/JCI85113

8. Dai YC, Zhong J, Xu JF. Regulatory B cells in infectious disease (review). Mol Med Rep (2017) 16(1):3-10. doi:10.3892/mmr.2017.6605

9. Wang S, Xia P, Chen Y, Qu Y, Xiong Z, Ye B, et al. Regulatory innate lymphoid cells control innate intestinal inflammation. Cell (2017) 171(1): 201-16.e18. doi:10.1016/j.cell.2017.07.027 
10. White AM, Wraith DC. Tr1-like T cells - an enigmatic regulatory T cell lineage. Front Immunol (2016) 7:355. doi:10.3389/fimmu.2016.00355

11. Wing JB, Sakaguchi S. Foxp3(+) T(reg) cells in humoral immunity. Int Immunol (2014) 26(2):61-9. doi:10.1093/intimm/dxt060

12. Lu L, Barbi J, Pan F. The regulation of immune tolerance by FOXP3. Nat Rev Immunol (2017) 17(11):703-17. doi:10.1038/nri.2017.75

13. Josefowicz SZ, Lu LF, Rudensky AY. Regulatory T cells: mechanisms of differentiation and function. Annu Rev Immunol (2012) 30:531-64. doi:10.1146/ annurev.immunol.25.022106.141623

14. Xing Y, Hogquist KA. T-cell tolerance: central and peripheral. Cold Spring Harb Perspect Biol (2012) 4(6):1-15. doi:10.1101/cshperspect.a006957

15. Surh CD, Sprent J. T-cell apoptosis detected in situ during positive and negative selection in the thymus. Nature (1994) 372(6501):100-3. doi:10.1038/ $372100 \mathrm{a} 0$

16. Moran AE, Hogquist KA. T-cell receptor affinity in thymic development. Immunology (2012) 135(4):261-7. doi:10.1111/j.1365-2567.2011. 03547.x

17. Nemazee D. Receptor editing in lymphocyte development and central tolerance. Nat Rev Immunol (2006) 6(10):728-40. doi:10.1038/nri1939

18. Cohen PL, Eisenberg RA. Lpr and gld: single gene models of systemic autoimmunity and lymphoproliferative disease. Annu Rev Immunol (1991) 9:243-69. doi:10.1146/annurev.iy.09.040191.001331

19. Sakaguchi S, Sakaguchi N, Asano M, Itoh M, Toda M. Immunologic selftolerance maintained by activated T cells expressing IL-2 receptor alphachains (CD25). Breakdown of a single mechanism of self-tolerance causes various autoimmune diseases. J Immunol (1995) 155(3):1151-64.

20. Nishizuka Y, Sakakura T. Ovarian dysgenesis induced by neonatal thymectomy in the mouse. Endocrinology (1971) 89(3):886-93. doi:10.1210/ endo-89-3-886

21. Taguchi O, Nishizuka Y, Sakakura T, Kojima A. Autoimmune oophoritis in thymectomized mice: detection of circulating antibodies against oocytes. Clin Exp Immunol (1980) 40(3):540-53.

22. Taguchi O, Nishizuka Y. Experimental autoimmune orchitis after neonatal thymectomy in the mouse. Clin Exp Immunol (1981) 46(2):425-34.

23. Kojima A, Tanaka-Kojima Y, Sakakura T, Nishizuka Y. Spontaneous development of autoimmune thyroiditis in neonatally thymectomized mice. Lab Invest (1976) 34(6):550-7.

24. Kojima A, Taguchi O, Nishizuka Y. Experimental production of possible autoimmune castritis followed by macrocytic anemia in athymic nude mice. Lab Invest (1980) 42(4):387-95.

25. Kojima A, Prehn RT. Genetic susceptibility to post-thymectomy autoimmune diseases in mice. Immunogenetics (1981) 14(1-2):15-27. doi:10.1007/ BF00344296

26. Penhale WJ, Irvine WJ, Inglis JR, Farmer A. Thyroiditis in T cell-depleted rats: suppression of the autoallergic response by reconstitution with normal lymphoid cells. Clin Exp Immunol (1976) 25(1):6-16.

27. Sakaguchi S, Fukuma K, Kuribayashi K, Masuda T. Organ-specific autoimmune diseases induced in mice by elimination of T cell subset. I. Evidence for the active participation of $\mathrm{T}$ cells in natural self-tolerance; deficit of a $\mathrm{T}$ cell subset as a possible cause of autoimmune disease. J Exp Med (1985) 161(1):72-87. doi:10.1084/jem.161.1.72

28. Powrie F, Leach MW, Mauze S, Caddle LB, Coffman RL. Phenotypically distinct subsets of $\mathrm{CD} 4+\mathrm{T}$ cells induce or protect from chronic intestinal inflammation in C. B-17 scid mice. Int Immunol (1993) 5(11):1461-71. doi:10.1093/intimm/5.11.1461

29. Morrissey PJ, Charrier K, Braddy S, Liggitt D, Watson JD. CD4+ T cells that express high levels of CD45RB induce wasting disease when transferred into congenic severe combined immunodeficient mice. Disease development is prevented by cotransfer of purified CD4+ T cells. J Exp Med (1993) 178(1):237-44. doi:10.1084/jem.178.1.237

30. Asano M, Toda M, Sakaguchi N, Sakaguchi S. Autoimmune disease as a consequence of developmental abnormality of a T cell subpopulation. J Exp Med (1996) 184(2):387-96. doi:10.1084/jem.184.2.387

31. Shevach EM. Regulatory T cells in autoimmmunity*. Annu Rev Immunol (2000) 18:423-49. doi:10.1146/annurev.immunol.18.1.423

32. Godfrey VL, Wilkinson JE, Rinchik EM, Russell LB. Fatal lymphoreticular disease in the scurfy (sf) mouse requires $\mathrm{T}$ cells that mature in a sf thymic environment: potential model for thymic education. Proc Natl Acad Sci U S A (1991) 88(13):5528-32. doi:10.1073/pnas.88.13.5528
33. Blair PJ, Bultman SJ, Haas JC, Rouse BT, Wilkinson JE, Godfrey VL. CD4+CD8- T cells are the effector cells in disease pathogenesis in the scurfy (sf) mouse. J Immunol (1994) 153(8):3764-74.

34. Kanangat S, Blair P, Reddy R, Daheshia M, Godfrey V, Rouse BT, et al. Disease in the scurfy (sf) mouse is associated with overexpression of cytokine genes. Eur J Immunol (1996) 26(1):161-5. doi:10.1002/eji.1830260125

35. Zahorsky-Reeves JL, Wilkinson JE. The murine mutation scurfy (sf) results in an antigen-dependent lymphoproliferative disease with altered $\mathrm{T}$ cell sensitivity. Eur J Immunol (2001) 31(1):196-204. doi:10.1002/1521-4141 (200101)31:1<196::AID-IMMU196>3.0.CO;2-9

36. Tivol EA, Borriello F, Schweitzer AN, Lynch WP, Bluestone JA, Sharpe AH. Loss of CTLA-4 leads to massive lymphoproliferation and fatal multiorgan tissue destruction, revealing a critical negative regulatory role of CTLA-4. Immunity (1995) 3(5):541-7. doi:10.1016/1074-7613(95)90125-6

37. Kulkarni AB, Huh CG, Becker D, Geiser A, Lyght M, Flanders KC, et al. Transforming growth factor beta 1 null mutation in mice causes excessive inflammatory response and early death. Proc Natl Acad Sci U S A (1993) 90(2):770-4. doi:10.1073/pnas.90.2.770

38. Brunkow ME, Jeffery EW, Hjerrild KA, Paeper B, Clark LB, Yasayko SA, et al. Disruption of a new forkhead/winged-helix protein, scurfin, results in the fatal lymphoproliferative disorder of the scurfy mouse. Nat Genet (2001) 27(1):68-73. doi:10.1038/83784

39. Bennett CL, Christie J, Ramsdell F, Brunkow ME, Ferguson PJ, Whitesell L, et al. The immune dysregulation, polyendocrinopathy, enteropathy, X-linked syndrome (IPEX) is caused by mutations of FOXP3. Nat Genet (2001) 27(1):20-1. doi:10.1038/83713

40. Wildin RS, Ramsdell F, Peake J, Faravelli F, Casanova JL, Buist N, et al. $\mathrm{X}$-linked neonatal diabetes mellitus, enteropathy and endocrinopathy syndrome is the human equivalent of mouse scurfy. Nat Genet (2001) 27(1):18-20. doi:10.1038/83707

41. Powell BR, Buist NR, Stenzel P. An X-linked syndrome of diarrhea, polyendocrinopathy, and fatal infection in infancy. J Pediatr (1982) 100(5):731-7. doi:10.1016/S0022-3476(82)80573-8

42. Khattri R, Cox T, Yasayko SA, Ramsdell F. An essential role for Scurfin in CD4+CD25+ T regulatory cells. Nat Immunol (2003) 4(4):337-42. doi: $10.1038 /$ ni909

43. Hori S, Nomura T, Sakaguchi S. Control of regulatory T cell development by the transcription factor Foxp3. Science (2003) 299(5609):1057-61. doi:10.1126/ science. 1079490

44. Fontenot JD, Gavin MA, Rudensky AY. Foxp3 programs the development and function of CD4+CD25+ regulatory T cells. Nat Immunol (2003) 4(4):330-6. doi:10.1038/ni904

45. Fontenot JD, Rasmussen JP, Williams LM, Dooley JL, Farr AG, Rudensky AY. Regulatory $\mathrm{T}$ cell lineage specification by the forkhead transcription factor foxp3. Immunity (2005) 22(3):329-41. doi:10.1016/j.immuni.2005. 01.016

46. Zheng Y, Josefowicz S, Chaudhry A, Peng XP, Forbush K, Rudensky AY. Role of conserved non-coding DNA elements in the Foxp3 gene in regulatory T-cell fate. Nature (2010) 463(7282):808-12. doi:10.1038/ nature 08750

47. Rudra D, deRoos P, Chaudhry A, Niec RE, Arvey A, Samstein RM, et al. Transcription factor Foxp3 and its protein partners form a complex regulatory network. Nat Immunol (2012) 13(10):1010-9. doi:10.1038/ni.2402

48. Hsieh CS, Lee HM, Lio CW. Selection of regulatory T cells in the thymus. Nat Rev Immunol (2012) 12(3):157-67. doi:10.1038/nri3155

49. Li MO, Rudensky AY. T cell receptor signalling in the control of regulatory $\mathrm{T}$ cell differentiation and function. Nat Rev Immunol (2016) 16(4):220-33. doi:10.1038/nri.2016.26

50. Hsieh CS, Zheng Y, Liang Y, Fontenot JD, Rudensky AY. An intersection between the self-reactive regulatory and nonregulatory $\mathrm{T}$ cell receptor repertoires. Nat Immunol (2006) 7(4):401-10. doi:10.1038/ni1318

51. Moran AE, Holzapfel KL, Xing Y, Cunningham NR, Maltzman JS, Punt J, et al. T cell receptor signal strength in Treg and iNKT cell development demonstrated by a novel fluorescent reporter mouse. JExp Med (2011) 208(6):1279-89. doi:10.1084/jem.20110308

52. Kitagawa Y, Ohkura N, Kidani Y, Vandenbon A, Hirota K, Kawakami R, et al. Guidance of regulatory T cell development by Satb1-dependent superenhancer establishment. Nat Immunol (2017) 18(2):173-83. doi:10.1038/ ni.3646 
53. Zhang X, Izikson L, Liu L, Weiner HL. Activation of CD25(+)CD4(+) regulatory $\mathrm{T}$ cells by oral antigen administration. J Immunol (2001) 167(8): 4245-53. doi:10.4049/jimmunol.167.8.4245

54. Mucida D, Kutchukhidze N, Erazo A, Russo M, Lafaille JJ, Curotto de Lafaille MA. Oral tolerance in the absence of naturally occurring Tregs. J Clin Invest (2005) 115(7):1923-33. doi:10.1172/JCI24487

55. Apostolou I, Sarukhan A, Klein L, von Boehmer H. Origin of regulatory T cells with known specificity for antigen. Nat Immunol (2002) 3(8):756-63. doi:10.1038/ni816

56. Takimoto T, Wakabayashi Y, Sekiya T, Inoue N, Morita R, Ichiyama K, et al. Smad2 and Smad3 are redundantly essential for the TGF-beta-mediated regulation of regulatory T plasticity and Th1 development. J Immunol (2010) 185(2):842-55. doi:10.4049/jimmunol.0904100

57. Chen W, Konkel JE. Development of thymic Foxp3(+) regulatory T cells: TGF-beta matters. Eur J Immunol (2015) 45(4):958-65. doi:10.1002/ eji.201444999

58. Ruan Q, Kameswaran V, Tone Y, Li L, Liou HC, Greene MI, et al. Development of Foxp3(+) regulatory t cells is driven by the c-Rel enhanceosome. Immunity (2009) 31(6):932-40. doi:10.1016/j.immuni.2009.10.006

59. Cretney E, Xin A, Shi W, Minnich M, Masson F, Miasari M, et al. The transcription factors Blimp-1 and IRF4 jointly control the differentiation and function of effector regulatory T cells. Nat Immunol (2011) 12(4):304-11. doi:10.1038/ni.2006

60. Smigiel KS, Richards E, Srivastava S, Thomas KR, Dudda JC, Klonowski KD, et al. CCR7 provides localized access to IL-2 and defines homeostatically distinct regulatory $\mathrm{T}$ cell subsets. J Exp Med (2014) 211(1):121-36. doi:10.1084/jem.20131142

61. Ito T, Hanabuchi S, Wang YH, Park WR, Arima K, Bover L, et al. Two functional subsets of FOXP3+ regulatory $\mathrm{T}$ cells in human thymus and periphery. Immunity (2008) 28(6):870-80. doi:10.1016/j.immuni.2008.03.018

62. Zheng Y, Chaudhry A, Kas A, deRoos P, Kim JM, Chu TT, et al. Regulatory T-cell suppressor program co-opts transcription factor IRF4 to control T(H)2 responses. Nature (2009) 458(7236):351-6. doi:10.1038/ nature 07674

63. Koch MA, Tucker-Heard G, Perdue NR, Killebrew JR, Urdahl KB, Campbell DJ. The transcription factor T-bet controls regulatory $\mathrm{T}$ cell homeostasis and function during type 1 inflammation. Nat Immunol (2009) 10(6):595-602. doi:10.1038/ni.1731

64. Chaudhry A, Rudra D, Treuting P, Samstein RM, Liang Y, Kas A, et al. CD4+ regulatory $\mathrm{T}$ cells control $\mathrm{TH} 17$ responses in a Stat3-dependent manner. Science (2009) 326(5955):986-91. doi:10.1126/science.1172702

65. Chaudhry A, Samstein RM, Treuting P, Liang Y, Pils MC, Heinrich JM, et al. Interleukin-10 signaling in regulatory $\mathrm{T}$ cells is required for suppression of Th17 cell-mediated inflammation. Immunity (2011) 34(4):566-78. doi:10.1016/j.immuni.2011.03.018

66. Chung Y, Tanaka S, Chu F, Nurieva RI, Martinez GJ, Rawal S, et al. Follicular regulatory T cells expressing Foxp3 and Bcl-6 suppress germinal center reactions. Nat Med (2011) 17(8):983-8. doi:10.1038/nm.2426

67. Linterman MA, Pierson W, Lee SK, Kallies A, Kawamoto S, Rayner TF, et al. Foxp3+ follicular regulatory $\mathrm{T}$ cells control the germinal center response. Nat Med (2011) 17(8):975-82. doi:10.1038/nm.2425

68. Virtanen KA, van Marken Lichtenbelt WD, Nuutila P. Brown adipose tissue functions in humans. Biochim Biophys Acta (2013) 1831(5):1004-8. doi:10.1016/j.bbalip.2012.12.011

69. Reue K. A thematic review series: lipid droplet storage and metabolism: from yeast to man. J Lipid Res (2011) 52(11):1865-8. doi:10.1194/jlr.E020602

70. Konige M, Wang H, Sztalryd C. Role of adipose specific lipid droplet proteins in maintaining whole body energy homeostasis. Biochim Biophys Acta (2014) 1842(3):393-401. doi:10.1016/j.bbadis.2013.05.007

71. Boutens L, Stienstra R. Adipose tissue macrophages: going off track during obesity. Diabetologia (2016) 59(5):879-94. doi:10.1007/s00125-016-3904-9

72. Trayhurn P. Hypoxia and adipose tissue function and dysfunction in obesity. Physiol Rev (2013) 93(1):1-21. doi:10.1152/physrev.00017.2012

73. Castoldi A, Naffah de Souza C, Camara NO, Moraes-Vieira PM. The macrophage switch in obesity development. Front Immunol (2015) 6:637. doi:10.3389/fimmu.2015.00637

74. O'Sullivan TE, Rapp M, Fan X, Weizman OE, Bhardwaj P, Adams NM, et al. Adipose-resident group 1 innate lymphoid cells promote obesity- associated insulin resistance. Immunity (2016) 45(2):428-41. doi:10.1016/j. immuni.2016.06.016

75. Nishimura S, Manabe I, Takaki S, Nagasaki M, Otsu M, Yamashita H, et al. Adipose natural regulatory B cells negatively control adipose tissue inflammation. Cell Metab (2013) 18:759-66. doi:10.1016/j.cmet.2013.09.017

76. Feuerer M, Herrero L, Cipolletta D, Naaz A, Wong J, Nayer A, et al. Lean, but not obese, fat is enriched for a unique population of regulatory $\mathrm{T}$ cells that affect metabolic parameters. Nat Med (2009) 15(8):930-9. doi: $10.1038 / \mathrm{nm} .2002$

77. Vasanthakumar A, Kallies A. The regulatory T cell: jack-of-all-trades. Trends Immunol (2015) 36(12):756-8. doi:10.1016/j.it.2015.10.002

78. Cipolletta D, Cohen P, Spiegelman BM, Benoist C, Mathis D. Appearance and disappearance of the mRNA signature characteristic of Treg cells in visceral adipose tissue: age, diet, and PPARgamma effects. Proc Natl Acad Sci U S A (2015) 112(2):482-7. doi:10.1073/pnas.1423486112

79. Bapat SP, Myoung Suh J, Fang S, Liu S, Zhang Y, Cheng A, et al. Depletion of fat-resident Treg cells prevents age-associated insulin resistance. Nature (2015) 528(7580):137-41. doi:10.1038/nature16151

80. Kolodin D, van Panhuys N, Li C, Magnuson AM, Cipolletta D, Miller CM, et al. Antigen- and cytokine-driven accumulation of regulatory $\mathrm{T}$ cells in visceral adipose tissue of lean mice. Cell Metab (2015) 21(4):543-57. doi:10.1016/j.cmet.2015.03.005

81. Correia-Neves M, Waltzinger C, Mathis D, Benoist C. The shaping of the $\mathrm{T}$ cell repertoire. Immunity (2001) 14(1):21-32. doi:10.1016/S10747613(01)00086-3

82. Kälin S, Becker M, Ott VB, Serr I, Hosp F, Mollah MMH, et al. A Stat6/ Pten axis links regulatory $\mathrm{T}$ cells with adipose tissue function. Cell Metab (2017) 26(3):475-92.e7. doi:10.1016/j.cmet.2017.08.008

83. Cipolletta D, Feuerer M, Li A, Kamei N, Lee J, Shoelson SE, et al. PPAR[ggr] is a major driver of the accumulation and phenotype of adipose tissue Treg cells. Nature (2012) 486(7404):549-53. doi:10.1038/nature11132

84. Vasanthakumar A, Moro K, Xin A, Liao Y, Gloury R, Kawamoto S, et al. The transcriptional regulators IRF4, BATF and IL-33 orchestrate development and maintenance of adipose tissue-resident regulatory $\mathrm{T}$ cells. Nat Immunol (2015) 16(3):276-85. doi:10.1038/ni.3085

85. Medrikova D, Sijmonsma TP, Sowodniok K, Richards DM, Delacher M, Sticht C, et al. Brown adipose tissue harbors a distinct sub-population of regulatory T cells. PLoS One (2015) 10(2):e0118534. doi:10.1371/journal. pone. 0118534

86. Hotamisligil GS, Shargill NS, Spiegelman BM. Adipose expression of tumor necrosis factor-alpha: direct role in obesity-linked insulin resistance. Science (1993) 259(5091):87-91. doi:10.1126/science.7678183

87. Xu H, Barnes GT, Yang Q, Tan G, Yang D, Chou CJ, et al. Chronic inflammation in fat plays a crucial role in the development of obesity-related insulin resistance. J Clin Invest (2003) 112(12):1821-30. doi:10.1172/JCI200319451

88. Ganguly D. Do type I interferons link systemic autoimmunities and metabolic syndrome in a pathogenetic continuum? Trends Immunol (2018) 39(1):28-43. doi:10.1016/j.it.2017.07.001

89. Wagner NM, Brandhorst G, Czepluch F, Lankeit M, Eberle C, Herzberg S, et al. Circulating regulatory $\mathrm{T}$ cells are reduced in obesity and may identify subjects at increased metabolic and cardiovascular risk. Obesity (Silver Spring) (2013) 21(3):461-8. doi:10.1002/oby.20087

90. Kim JM, Rasmussen JP, Rudensky AY. Regulatory T cells prevent catastrophic autoimmunity throughout the lifespan of mice. Nat Immunol (2007) 8(2):191-7. doi:10.1038/nil428

91. Smith U. Pioglitazone: mechanism of action. Int J Clin Pract Suppl (2001) (121):13-8.

92. Carobbio S, Pellegrinelli V, Vidal-Puig A. Adipose tissue function and expandability as determinants of lipotoxicity and the metabolic syndrome. Adv Exp Med Biol (2017) 960:161-96. doi:10.1007/978-3-319-48382-5_7

93. Wernstedt Asterholm I, Tao C, Morley TS, Wang QA, Delgado-Lopez F, Wang ZV, et al. Adipocyte inflammation is essential for healthy adipose tissue expansion and remodeling. Cell Metab (2014) 20(1):103-18. doi:10.1016/j. cmet.2014.05.005

94. Kim JY, van de Wall E, Laplante M, Azzara A, Trujillo ME, Hofmann SM, et al. Obesity-associated improvements in metabolic profile through expansion of adipose tissue. J Clin Invest (2007) 117(9):2621-37. doi:10.1172/ JCI31021 
95. Rothwell NJ, Stock MJ. A role for brown adipose tissue in diet-induced thermogenesis. Nature (1979) 281(5726):31-5. doi:10.1038/281031a0

96. Sender R, Fuchs S, Milo R. Are we really vastly outnumbered? Revisiting the ratio of bacterial to host cells in humans. Cell (2016) 164(3):337-40. doi:10.1016/j.cell.2016.01.013

97. Sender R, Fuchs S, Milo R. Revised estimates for the number of human and bacteria cells in the body. PLoS Biol (2016) 14(8):e1002533. doi:10.1371/ journal.pbio. 1002533

98. Shapira M. Gut microbiotas and host evolution: scaling up symbiosis. Trends Ecol Evol (2016) 31(7):539-49. doi:10.1016/j.tree.2016.03.006

99. Powell DW, Pinchuk IV, Saada JI, Chen X, Mifflin RC. Mesenchymal cells of the intestinal lamina propria. Annu Rev Physiol (2011) 73:213-37. doi:10.1146/annurev.physiol.70.113006.100646

100. Yang Y, Zhang Y, Cao Z, Ji H, Yang X, Iwamoto H, et al. Anti-VEGF- and anti-VEGF receptor-induced vascular alteration in mouse healthy tissues. Proc Natl Acad Sci U S A (2013) 110(29):12018-23. doi:10.1073/pnas. 1301331110

101. Mowat AM, Agace WW. Regional specialization within the intestinal immune system. Nat Rev Immunol (2014) 14(10):667-85. doi:10.1038/nri3738

102. Johansson ME, Phillipson M, Petersson J, Velcich A, Holm L, Hansson GC. The inner of the two Muc2 mucin-dependent mucus layers in colon is devoid of bacteria. Proc Natl Acad Sci U S A (2008) 105(39):15064-9. doi:10.1073/ pnas. 0803124105

103. Li H, Limenitakis JP, Fuhrer T, Geuking MB, Lawson MA, Wyss M, et al. The outer mucus layer hosts a distinct intestinal microbial niche. Nat Commun (2015) 6:8292. doi:10.1038/ncomms9292

104. Bernier-Latmani J, Petrova TV. Intestinal lymphatic vasculature: structure, mechanisms and functions. Nat Rev Gastroenterol Hepatol (2017) 14(9): 510-26. doi:10.1038/nrgastro.2017.79

105. Tanoue T, Atarashi K, Honda K. Development and maintenance of intestinal regulatory T cells. Nat Rev Immunol (2016) 16(5):295-309. doi:10.1038/ nri.2016.36

106. Panduro M, Benoist C, Mathis D. Tissue Tregs. Annu Rev Immunol (2016) 34:609-33. doi:10.1146/annurev-immunol-032712-095948

107. Sefik E, Geva-Zatorsky N, Oh S, Konnikova L, Zemmour D, McGuire AM, et al. MUCOSAL IMMUNOLOGY. Individual intestinal symbionts induce a distinct population of RORgamma(+) regulatory T cells. Science (2015) 349(6251):993-7. doi:10.1126/science.aaa9420

108. Schiering C, Krausgruber T, Chomka A, Frohlich A, Adelmann K, Wohlfert EA, et al. The alarmin IL-33 promotes regulatory T-cell function in the intestine. Nature (2014) 513(7519):564-8. doi:10.1038/nature13577

109. Kim KS, Hong SW, Han D, Yi J, Jung J, Yang BG, et al. Dietary antigens limit mucosal immunity by inducing regulatory $\mathrm{T}$ cells in the small intestine. Science (2016) 351(6275):858-63. doi:10.1126/science.aac5560

110. Wohlfert EA, Grainger JR, Bouladoux N, Konkel JE, Oldenhove G, Ribeiro $\mathrm{CH}$, et al. GATA3 controls Foxp3(+) regulatory T cell fate during inflammation in mice. JClin Invest (2011) 121(11):4503-15. doi:10.1172/ JCI57456

111. Atarashi K, Tanoue T, Shima T, Imaoka A, Kuwahara T, Momose Y, et al. Induction of colonic regulatory $\mathrm{T}$ cells by indigenous Clostridium species. Science (2011) 331(6015):337-41. doi:10.1126/science.1198469

112. Geuking MB, Cahenzli J, Lawson MA, Ng DC, Slack E, Hapfelmeier S, et al. Intestinal bacterial colonization induces mutualistic regulatory $\mathrm{T}$ cell responses. Immunity (2011) 34(5):794-806. doi:10.1016/j.immuni.2011. 03.021

113. Lathrop SK, Bloom SM, Rao SM, Nutsch K, Lio CW, Santacruz N, et al. Peripheral education of the immune system by colonic commensal microbiota. Nature (2011) 478(7368):250-4. doi:10.1038/nature10434

114. Nutsch K, Chai JN, Ai TL, Russler-Germain E, Feehley T, Nagler CR, et al. Rapid and efficient generation of regulatory $\mathrm{T}$ cells to commensal antigens in the periphery. Cell Rep (2016) 17(1):206-20. doi:10.1016/j. celrep.2016.08.092

115. Thornton AM, Korty PE, Tran DQ, Wohlfert EA, Murray PE, Belkaid Y, et al. Expression of Helios, an Ikaros transcription factor family member, differentiates thymic-derived from peripherally induced Foxp $3+\mathrm{T}$ regulatory cells. J Immunol (2010) 184(7):3433-41. doi:10.4049/jimmunol.0904028

116. Weiss JM, Bilate AM, Gobert M, Ding Y, Curotto de Lafaille MA, Parkhurst CN, et al. Neuropilin 1 is expressed on thymus-derived natural regulatory $\mathrm{T}$ cells, but not mucosa-generated induced Foxp3+ T reg cells. J Exp Med (2012) 209(10):1723-42, S1. doi:10.1084/jem.20120914

117. Yadav M, Louvet C, Davini D, Gardner JM, Martinez-Llordella M, Bailey-Bucktrout $\mathrm{S}$, et al. Neuropilin-1 distinguishes natural and inducible regulatory T cells among regulatory $\mathrm{T}$ cell subsets in vivo. J Exp Med (2012) 209(10):1713-22, S1-19. doi:10.1084/jem.20120822

118. Gottschalk RA, Corse E, Allison JP. Expression of Helios in peripherally induced Foxp3+ regulatory T cells. J Immunol (2012) 188(3):976-80. doi:10.4049/ jimmunol.1102964

119. Szurek E, Cebula A, Wojciech L, Pietrzak M, Rempala G, Kisielow P, et al. Differences in expression level of Helios and neuropilin-1 do not distinguish thymus-derived from extrathymically-induced CD4+Foxp3+ regulatory T cells. PLoS One (2015) 10(10):e0141161. doi:10.1371/journal. pone. 0141161

120. Xu L, Kitani A, Stuelten C, McGrady G, Fuss I, Strober W. Positive and negative transcriptional regulation of the Foxp3 gene is mediated by access and binding of the Smad3 protein to enhancer I. Immunity (2010) 33(3):313-25. doi:10.1016/j.immuni.2010.09.001

121. Coombes JL, Siddiqui KR, Arancibia-Carcamo CV, Hall J, Sun CM, Belkaid Y, et al. A functionally specialized population of mucosal CD103+ DCs induces Foxp3+ regulatory T cells via a TGF-beta and retinoic aciddependent mechanism. J Exp Med (2007) 204(8):1757-64. doi:10.1084/ jem. 20070590

122. Hill JA, Hall JA, Sun CM, Cai Q, Ghyselinck N, Chambon P, et al. Retinoic acid enhances Foxp3 induction indirectly by relieving inhibition from CD4+CD44hi Cells. Immunity (2008) 29(5):758-70. doi:10.1016/j.immuni. 2008.09.018

123. Cebula A, Seweryn M, Rempala GA, Pabla SS, McIndoe RA, Denning TL, et al. Thymus-derived regulatory $\mathrm{T}$ cells contribute to tolerance to commensal microbiota. Nature (2013) 497(7448):258-62. doi:10.1038/nature12079

124. Korn LL, Hubbeling HG, Porrett PM, Yang Q, Barnett LG, Laufer TM. Regulatory T cells occupy an isolated niche in the intestine that is antigen independent. Cell Rep (2014) 9(5):1567-73. doi:10.1016/j.celrep.2014.11.006

125. Wang Y, Su MA, Wan YY. An essential role of the transcription factor GATA-3 for the function of regulatory T cells. Immunity (2011) 35(3):337-48. doi:10.1016/j.immuni.2011.08.012

126. Bertheloot D, Latz E. HMGB1, IL-1alpha, IL-33 and S100 proteins: dual-function alarmins. Cell Mol Immunol (2017) 14(1):43-64. doi:10.1038/ cmi.2016.34

127. Chan JK, Roth J, Oppenheim JJ, Tracey KJ, Vogl T, Feldmann M, et al. Alarmins: awaiting a clinical response. J Clin Invest (2012) 122(8):2711-9. doi:10.1172/JCI62423

128. Siede J, Frohlich A, Datsi A, Hegazy AN, Varga DV, Holecska V, et al. IL-33 receptor-expressing regulatory $\mathrm{T}$ cells are highly activated, $\mathrm{Th} 2$ biased and suppress CD4 T cell proliferation through IL-10 and TGFbeta release. PLoS One (2016) 11(8):e0161507. doi:10.1371/journal.pone.0161507

129. Ohnmacht C, Park JH, Cording S, Wing JB, Atarashi K, Obata Y, et al. MUCOSAL IMMUNOLOGY. The microbiota regulates type 2 immunity through RORgammat(+) T cells. Science (2015) 349(6251):989-93. doi:10.1126/ science.aac 4263

130. Yang BH, Hagemann S, Mamareli P, Lauer U, Hoffmann U, Beckstette M, et al. Foxp3(+) T cells expressing RORgammat represent a stable regulatory T-cell effector lineage with enhanced suppressive capacity during intestinal inflammation. Mucosal Immunol (2016) 9(2):444-57. doi:10.1038/mi.2015.74

131. Li X, Liang Y, LeBlanc M, Benner C, Zheng Y. Function of a Foxp3 ciselement in protecting regulatory $\mathrm{T}$ cell identity. Cell (2014) 158(4):734-48. doi:10.1016/j.cell.2014.07.030

132. Davie JR. Inhibition of histone deacetylase activity by butyrate. J Nutr (2003) 133(7 Suppl):2485S-93S. doi:10.1093/jn/133.7.2485S

133. Arpaia N, Campbell C, Fan X, Dikiy S, van der Veeken J, deRoos P, et al. Metabolites produced by commensal bacteria promote peripheral regulatory T-cell generation. Nature (2013) 504(7480):451-5. doi:10.1038/nature12726

134. Furusawa Y, Obata Y, Fukuda S, Endo TA, Nakato G, Takahashi D, et al. Commensal microbe-derived butyrate induces the differentiation of colonic regulatory T cells. Nature (2013) 504(7480):446-50. doi:10.1038/ nature 12721

135. Zhu HC, Qiu T, Liu XH, Dong WC, Weng XD, Hu CH, et al. Tolerogenic dendritic cells generated by RelB silencing using shRNA prevent acute 
rejection. Cell Immunol (2012) 274(1-2):12-8. doi:10.1016/j.cellimm. 2012.02.012

136. Shih VF, Davis-Turak J, Macal M, Huang JQ, Ponomarenko J, Kearns JD, et al. Control of RelB during dendritic cell activation integrates canonical and noncanonical NF-kappaB pathways. Nat Immunol (2012) 13(12): 1162-70. doi:10.1038/ni.2446

137. Frank DN, St Amand AL, Feldman RA, Boedeker EC, Harpaz N, Pace NR. Molecular-phylogenetic characterization of microbial community imbalances in human inflammatory bowel diseases. Proc Natl Acad Sci U S A (2007) 104(34):13780-5. doi:10.1073/pnas.0706625104

138. Thibault R, De Coppet P, Daly K, Bourreille A, Cuff M, Bonnet C, et al. Down-regulation of the monocarboxylate transporter 1 is involved in butyrate deficiency during intestinal inflammation. Gastroenterology (2007) 133(6): 1916-27. doi:10.1053/j.gastro.2007.08.041

139. Xu M, Pokrovskii M, Ding Y, Yi R, Au C, Harrison OJ, et al. c-MAFdependent regulatory $\mathrm{T}$ cells mediate immunological tolerance to a gut pathobiont. Nature (2018) 554:373-7. doi:10.1038/nature25500

140. Xu J, Yang Y, Qiu G, Lal G, Wu Z, Levy DE, et al. c-Maf regulates IL-10 expression during Th17 polarization. JImmunol (2009) 182(10):6226-36. doi:10.4049/jimmunol.0900123

141. Konkel JE, Zhang D, Zanvit P, Chia C, Zangarle-Murray T, Jin W, et al. Transforming growth factor-beta signaling in regulatory $\mathrm{T}$ cells controls $\mathrm{T}$ helper-17 cells and tissue-specific immune responses. Immunity (2017) 46(4):660-74. doi:10.1016/j.immuni.2017.03.015

142. Li MO, Flavell RA. TGF-beta: a master of all T cell trades. Cell (2008) 134(3):392-404. doi:10.1016/j.cell.2008.07.025

143. Rubtsov YP, Rudensky AY. TGFbeta signalling in control of T-cell-mediated self-reactivity. Nat Rev Immunol (2007) 7(6):443-53. doi:10.1038/nri2095

144. Zeng H, Chi H. Metabolic control of regulatory T cell development and function. Trends Immunol (2015) 36(1):3-12. doi:10.1016/j.it.2014.08.003

145. Sun CM, Hall JA, Blank RB, Bouladoux N, Oukka M, Mora JR, et al. Small intestine lamina propria dendritic cells promote de novo generation of Foxp3 T reg cells via retinoic acid. J Exp Med (2007) 204(8):1775-85. doi:10.1084/jem.20070602

146. Bakdash G, Vogelpoel LT, van Capel TM, Kapsenberg ML, de Jong EC. Retinoic acid primes human dendritic cells to induce gut-homing, IL-10producing regulatory T cells. Mucosal Immunol (2015) 8(2):265-78. doi:10.1038/mi.2014.64

147. Kang SW, Kim SH, Lee N, Lee WW, Hwang KA, Shin MS, et al. 1,25Dihyroxyvitamin D3 promotes FOXP3 expression via binding to vitamin D response elements in its conserved noncoding sequence region. JImmunol (2012) 188(11):5276-82. doi:10.4049/jimmunol.1101211

148. Lu D, Lan B, Din Z, Chen H, Chen G. A vitamin D receptor agonist converts $\mathrm{CD} 4+\mathrm{T}$ cells to Foxp3+ regulatory $\mathrm{T}$ cells in patients with ulcerative colitis. Oncotarget (2017) 8(32):53552-62. doi:10.18632/oncotarget.18614

149. Zaiss DM, van Loosdregt J, Gorlani A, Bekker CP, Grone A, Sibilia M, et al. Amphiregulin enhances regulatory $\mathrm{T}$ cell-suppressive function via the epidermal growth factor receptor. Immunity (2013) 38(2):275-84. doi:10.1016/j.immuni.2012.09.023

150. Arpaia N, Green JA, Moltedo B, Arvey A, Hemmers S, Yuan S, et al. A distinct function of regulatory T cells in tissue protection. Cell (2015) 162(5):1078-89. doi:10.1016/j.cell.2015.08.021

151. Green JA, Arpaia N, Schizas M, Dobrin A, Rudensky AY. A nonimmune function of T cells in promoting lung tumor progression. J Exp Med (2017) 214(12):3565-75. doi:10.1084/jem.20170356

152. Sujino T, London M, Hoytema van Konijnenburg DP, Rendon T, Buch T, Silva HM, et al. Tissue adaptation of regulatory and intraepithelial CD4(+) $\mathrm{T}$ cells controls gut inflammation. Science (2016) 352(6293):1581-6. doi:10.1126/science.aaf3892

153. Hoytema van Konijnenburg DP, Mucida D. Intraepithelial lymphocytes. Curr Biol (2017) 27(15):R737-9. doi:10.1016/j.cub.2017.05.073

154. Di Meglio P, Perera GK, Nestle FO. The multitasking organ: recent insights into skin immune function. Immunity (2011) 35(6):857-69. doi:10.1016/j. immuni.2011.12.003

155. Kanitakis J. Anatomy, histology and immunohistochemistry of normal human skin. Eur J Dermatol (2002) 12(4):390-9.

156. Halabi-Tawil M, Ruemmele FM, Fraitag S, Rieux-Laucat F, Neven B, Brousse $\mathrm{N}$, et al. Cutaneous manifestations of immune dysregulation, polyendocrinopathy, enteropathy, X-linked (IPEX) syndrome. $\mathrm{Br} J$ Dermatol (2009) 160(3):645-51. doi:10.1111/j.1365-2133.2008.08835.x

157. Sanchez Rodriguez R, Pauli ML, Neuhaus IM, Yu SS, Arron ST, Harris HW, et al. Memory regulatory T cells reside in human skin. J Clin Invest (2014) 124(3):1027-36. doi:10.1172/JCI72932

158. Ali N, Zirak B, Rodriguez RS, Pauli ML, Truong HA, Lai K, et al. Regulatory $\mathrm{T}$ cells in skin facilitate epithelial stem cell differentiation. Cell (2017) 169(6):1119-29.e11. doi:10.1016/j.cell.2017.05.002

159. Scharschmidt TC, Vasquez KS, Truong HA, Gearty SV, Pauli ML, Nosbaum A, et al. A wave of regulatory $\mathrm{T}$ cells into neonatal skin mediates tolerance to commensal microbes. Immunity (2015) 43(5):1011-21. doi:10.1016/j. immuni.2015.10.016

160. Povoleri GA, Scotta C, Nova-Lamperti EA, John S, Lombardi G, Afzali B. Thymic versus induced regulatory $\mathrm{T}$ cells - who regulates the regulators? Front Immunol (2013) 4:169. doi:10.3389/fimmu.2013.00169

161. Huehn J, Polansky JK, Hamann A. Epigenetic control of FOXP3 expression: the key to a stable regulatory T-cell lineage? Nat Rev Immunol (2009) 9(2):83-9. doi:10.1038/nri2474

162. Hadeiba H, Lahl K, Edalati A, Oderup C, Habtezion A, Pachynski R, et al. Plasmacytoid dendritic cells transport peripheral antigens to the thymus to promote central tolerance. Immunity (2012) 36(3):438-50. doi:10.1016/j. immuni.2012.01.017

163. Kohli K, Janssen A, Forster R. Plasmacytoid dendritic cells induce tolerance predominantly by cargoing antigen to lymph nodes. Eur J Immunol (2016) 46(11):2659-68. doi:10.1002/eji.201646359

164. Nestle FO, Conrad C, Tun-Kyi A, Homey B, Gombert M, Boyman O, et al. Plasmacytoid predendritic cells initiate psoriasis through interferon-alpha production. J Exp Med (2005) 202(1):135-43. doi:10.1084/jem.20050500

165. Gregorio J, Meller S, Conrad C, Di Nardo A, Homey B, Lauerma A, et al. Plasmacytoid dendritic cells sense skin injury and promote wound healing through type I interferons. J Exp Med (2010) 207(13):2921-30. doi:10.1084/ jem.20101102

166. Rosenblum MD, Gratz IK, Paw JS, Lee K, Marshak-Rothstein A, Abbas AK. Response to self antigen imprints regulatory memory in tissues. Nature (2011) 480(7378):538-42. doi:10.1038/nature10664

167. van der Veeken J, Gonzalez AJ, Cho H, Arvey A, Hemmers S, Leslie CS, et al. Memory of inflammation in regulatory T cells. Cell (2016) 166:977-90. doi:10.1016/j.cell.2016.07.006

168. Sather BD, Treuting P, Perdue N, Miazgowicz M, Fontenot JD, Rudensky AY, et al. Altering the distribution of Foxp3(+) regulatory $\mathrm{T}$ cells results in tissue-specific inflammatory disease. J Exp Med (2007) 204(6):1335-47. doi:10.1084/jem.20070081

169. Campbell JJ, Haraldsen G, Pan J, Rottman J, Qin S, Ponath P, et al. The chemokine receptor CCR4 in vascular recognition by cutaneous but not intestinal memory T cells. Nature (1999) 400(6746):776-80. doi:10.1038/23495

170. Horikawa T, Nakayama T, Hikita I, Yamada H, Fujisawa R, Bito T, et al. IFN-gamma-inducible expression of thymus and activation-regulated chemokine/CCL17 and macrophage-derived chemokine/CCL22 in epidermal keratinocytes and their roles in atopic dermatitis. Int Immunol (2002) 14(7):767-73. doi:10.1093/intimm/dxf044

171. Yoshie O, Matsushima K. CCR4 and its ligands: from bench to bedside. Int Immunol (2015) 27(1):11-20. doi:10.1093/intimm/dxu079

172. Mariani M, Lang R, Binda E, Panina-Bordignon P, D'Ambrosio D. Dominance of CCL22 over CCL17 in induction of chemokine receptor CCR4 desensitization and internalization on human Th2 cells. Eur J Immunol (2004) 34(1):231-40. doi:10.1002/eji.200324429

173. Belkaid Y, Hand TW. Role of the microbiota in immunity and inflammation. Cell (2014) 157(1):121-41. doi:10.1016/j.cell.2014.03.011

174. Belkaid Y, Segre JA. Dialogue between skin microbiota and immunity. Science (2014) 346(6212):954-9. doi:10.1126/science.1260144

175. Yang S, Fujikado N, Kolodin D, Benoist C, Mathis D. Immune tolerance. Regulatory $\mathrm{T}$ cells generated early in life play a distinct role in maintaining self-tolerance. Science (2015) 348(6234):589-94. doi:10.1126/science. aaa7017

176. Sardella C, Winkler C, Quignodon L, Hardman JA, Toffoli B, Giordano Attianese GMP, et al. Delayed hair follicle morphogenesis and hair follicle dystrophy in a lipoatrophy mouse model of Pparg total deletion. J Invest Dermatol (2018) 138(3):500-10. doi:10.1016/j.jid.2017.09.024 
177. Coulson-Thomas VJ, Gesteira TF, Esko J, Kao W. Heparan sulfate regulates hair follicle and sebaceous gland morphogenesis and homeostasis. J Biol Chem (2014) 289(36):25211-26. doi:10.1074/jbc.M114.572511

178. Nagao K, Kobayashi T, Moro K, Ohyama M, Adachi T, Kitashima DY, et al. Stress-induced production of chemokines by hair follicles regulates the trafficking of dendritic cells in skin. Nat Immunol (2012) 13(8):744-52. doi:10.1038/ni.2353

179. Scharschmidt TC, Vasquez KS, Pauli ML, Leitner EG, Chu K, Truong HA, et al. Commensal microbes and hair follicle morphogenesis coordinately drive Treg migration into neonatal skin. Cell Host Microbe (2017) 21(4): 467-77.e5. doi:10.1016/j.chom.2017.03.001

180. Naik S, Bouladoux N, Wilhelm C, Molloy MJ, Salcedo R, Kastenmuller W, et al. Compartmentalized control of skin immunity by resident commensals. Science (2012) 337(6098):1115-9. doi:10.1126/science.1225152

181. Yamazaki S, Nishioka A, Kasuya S, Ohkura N, Hemmi H, Kaisho T, et al. Homeostasis of thymus-derived Foxp3+ regulatory $\mathrm{T}$ cells is controlled by ultraviolet B exposure in the skin. JImmunol (2014) 193(11):5488-97. doi:10.4049/jimmunol.1400985

182. Bernard JJ, Cowing-Zitron C, Nakatsuji T, Muehleisen B, Muto J, Borkowski AW, et al. Ultraviolet radiation damages self noncoding RNA and is detected by TLR3. Nat Med (2012) 18(8):1286-90. doi:10.1038/nm.2861

183. Racz E, Prens EP. Phototherapy of psoriasis, a chronic inflammatory skin disease. Adv Exp Med Biol (2017) 996:287-94. doi:10.1007/978-3-319-56017-5_24

184. Davis DM, Borok J, Udkoff J, Lio P, Spergel J. Atopic dermatitis: phototherapy and systemic therapy. Semin Cutan Med Surg (2017) 36(3):118-23. doi:10.12788/j.sder.2017.027

185. Fujisaki J, Wu J, Carlson AL, Silberstein L, Putheti P, Larocca R, et al. In vivo imaging of Treg cells providing immune privilege to the haematopoietic stem-cell niche. Nature (2011) 474(7350):216-9. doi:10.1038/ nature 10160

186. Nosbaum A, Prevel N, Truong HA, Mehta P, Ettinger M, Scharschmidt TC, et al. Cutting edge: regulatory $\mathrm{T}$ cells facilitate cutaneous wound healing. J Immunol (2016) 196(5):2010-4. doi:10.4049/jimmunol.1502139

187. Bodnar RJ. Epidermal growth factor and epidermal growth factor receptor: the Yin and Yang in the treatment of cutaneous wounds and cancer. $A d v$ Wound Care (New Rochelle) (2013) 2(1):24-9. doi:10.1089/wound.2011.0326

188. Burzyn D, Kuswanto W, Kolodin D, Shadrach JL, Cerletti M, Jang Y, et al. A special population of regulatory $\mathrm{T}$ cells potentiates muscle repair. Cell (2013) 155(6):1282-95. doi:10.1016/j.cell.2013.10.054

189. Dvorak HF. Tumors: wounds that do not heal. Similarities between tumor stroma generation and wound healing. N Engl J Med (1986) 315(26):1650-9. doi:10.1056/NEJM198612253152606

190. Dvorak HF. Tumors: wounds that do not heal-redux. Cancer Immunol Res (2015) 3(1):1-11. doi:10.1158/2326-6066.CIR-14-0209

191. Balkwill F, Mantovani A. Inflammation and cancer: back to Virchow? Lancet (2001) 357(9255):539-45. doi:10.1016/S0140-6736(00)04046-0

192. Zheng C, Zheng L, Yoo JK, Guo H, Zhang Y, Guo X, et al. Landscape of infiltrating $\mathrm{T}$ cells in liver cancer revealed by single-cell sequencing. Cell (2017) 169(7):1342-56.e16. doi:10.1016/j.cell.2017.05.035

193. Nagase H, Takeoka T, Urakawa S, Morimoto-Okazawa A, Kawashima A, Iwahori K, et al. ICOS(+) Foxp3(+) TILs in gastric cancer are prognostic markers and effector regulatory $\mathrm{T}$ cells associated with Helicobacter pylori. Int J Cancer (2017) 140(3):686-95. doi:10.1002/ijc.30475

194. Akimova T, Zhang T, Negorev D, Singhal S, Stadanlick J, Rao A, et al. Human lung tumor FOXP3+ Tregs upregulate four "Treg-locking" transcription factors. JCI Insight (2017) 2(16):1-20. doi:10.1172/jci.insight.94075

195. Loyher PL, Rochefort J, Baudesson de Chanville C, Hamon P, Lescaille G, Bertolus $\mathrm{C}$, et al. CCR2 influences $\mathrm{T}$ regulatory cell migration to tumors and serves as a biomarker of cyclophosphamide sensitivity. Cancer Res (2016) 76(22):6483-94. doi:10.1158/0008-5472.CAN-16-0984

196. You Y, Li Y, Li M, Lei M, Wu M, Qu Y, et al. Ovarian cancer stem cells promote tumour immune privilege and invasion via CCL5 and regulatory T cells. Clin Exp Immunol (2018) 191(1):60-73. doi:10.1111/cei.13044

197. Tang Y, Xu X, Guo S, Zhang C, Tang Y, Tian Y, et al. An increased abundance of tumor-infiltrating regulatory $\mathrm{T}$ cells is correlated with the progression and prognosis of pancreatic ductal adenocarcinoma. PLoS One (2014) 9(3):e91551. doi:10.1371/journal.pone.0091551

198. Vence L, Palucka AK, Fay JW, Ito T, Liu YJ, Banchereau J, et al. Circulating tumor antigen-specific regulatory $\mathrm{T}$ cells in patients with metastatic melanoma. Proc Natl Acad Sci U S A (2007) 104(52):20884-9. doi:10.1073/ pnas.0710557105

199. Overacre-Delgoffe AE, Chikina M, Dadey RE, Yano H, Brunazzi EA, Shayan G, et al. Interferon-gamma drives Treg fragility to promote antitumor immunity. Cell (2017) 169(6):1130-41.e11. doi:10.1016/j.cell.2017. 05.005

200. Salama P, Phillips M, Grieu F, Morris M, Zeps N, Joseph D, et al. Tumorinfiltrating FOXP3+ T regulatory cells show strong prognostic significance in colorectal cancer. JClin Oncol (2009) 27(2):186-92. doi:10.1200/JCO. 2008.18.7229

201. Frey DM, Droeser RA, Viehl CT, Zlobec I, Lugli A, Zingg U, et al. High frequency of tumor-infiltrating FOXP3(+) regulatory T cells predicts improved survival in mismatch repair-proficient colorectal cancer patients. Int J Cancer (2010) 126(11):2635-43. doi:10.1002/ijc.24989

202. Sinicrope FA, Rego RL, Ansell SM, Knutson KL, Foster NR, Sargent DJ. Intraepithelial effector $(\mathrm{CD} 3+)$ /regulatory (FoxP3+) T-cell ratio predicts a clinical outcome of human colon carcinoma. Gastroenterology (2009) 137(4): 1270-9. doi:10.1053/j.gastro.2009.06.053

203. Miyara M, Yoshioka Y, Kitoh A, Shima T, Wing K, Niwa A, et al. Functional delineation and differentiation dynamics of human CD4+ T cells expressing the FoxP3 transcription factor. Immunity (2009) 30(6):899-911. doi:10.1016/j.immuni.2009.03.019

204. Sakaguchi S, Miyara M, Costantino CM, Hafler DA. FOXP3+ regulatory T cells in the human immune system. Nat Rev Immunol (2010) 10(7):490-500. doi:10.1038/nri2785

205. Saito T, Nishikawa H, Wada H, Nagano Y, Sugiyama D, Atarashi K, et al. Two FOXP3(+)CD4(+) T cell subpopulations distinctly control the prognosis of colorectal cancers. Nat Med (2016) 22(6):679-84. doi:10.1038/nm.4086

206. Stover DG, Bierie B, Moses HL. A delicate balance: TGF-beta and the tumor microenvironment. J Cell Biochem (2007) 101(4):851-61. doi:10.1002/jcb.21149

207. Pickup M, Novitskiy S, Moses HL. The roles of TGFbeta in the tumour microenvironment. Nat Rev Cancer (2013) 13(11):788-99. doi:10.1038/nrc3603

208. Bilate AM, Lafaille JJ. Induced CD4+Foxp3+ regulatory T cells in immune tolerance. Annu Rev Immunol (2012) 30:733-58. doi:10.1146/annurevimmunol-020711-075043

209. Getnet D, Maris CH, Hipkiss EL, Grosso JF, Harris TJ, Yen HR, et al. Tumor recognition and self-recognition induce distinct transcriptional profiles in antigen-specific CD4 T cells. J Immunol (2009) 182(8):4675-85. doi:10.4049/jimmunol.0803400

210. Zhou G, Levitsky HI. Natural regulatory $T$ cells and de novo-induced regulatory $\mathrm{T}$ cells contribute independently to tumor-specific tolerance. J Immunol (2007) 178(4):2155-62. doi:10.4049/jimmunol.178.4.2155

211. van Rooij N, van Buuren MM, Philips D, Velds A, Toebes M, Heemskerk B, et al. Tumor exome analysis reveals neoantigen-specific T-cell reactivity in an ipilimumab-responsive melanoma. J Clin Oncol (2013) 31(32):e439-42. doi:10.1200/JCO.2012.47.7521

212. Cohen CJ, Gartner JJ, Horovitz-Fried M, Shamalov K, Trebska-McGowan K, Bliskovsky VV, et al. Isolation of neoantigen-specific T cells from tumor and peripheral lymphocytes. J Clin Invest (2015) 125(10):3981-91. doi:10.1172/ JCI82416

213. Johanns TM, Ward JP, Miller CA, Wilson C, Kobayashi DK, Bender D, et al. Endogenous neoantigen-specific CD8 T cells identified in two glioblastoma models using a cancer immunogenomics approach. Cancer Immunol Res (2016) 4(12):1007-15. doi:10.1158/2326-6066.CIR-16-0156

214. Malchow S, Leventhal DS, Nishi S, Fischer BI, Shen L, Paner GP, et al. Aire-dependent thymic development of tumor-associated regulatory $\mathrm{T}$ cells. Science (2013) 339(6124):1219-24. doi:10.1126/science.1233913

215. Hindley JP, Ferreira C, Jones E, Lauder SN, Ladell K, Wynn KK, et al. Analysis of the T-cell receptor repertoires of tumor-infiltrating conventional and regulatory $\mathrm{T}$ cells reveals no evidence for conversion in carcinogeninduced tumors. Cancer Res (2011) 71(3):736-46. doi:10.1158/0008-5472. CAN-10-1797

216. Sainz-Perez A, Lim A, Lemercier B, Leclerc C. The T-cell receptor repertoire of tumor-infiltrating regulatory $\mathrm{T}$ lymphocytes is skewed toward public sequences. Cancer Res (2012) 72(14):3557-69. doi:10.1158/0008-5472.CAN12-0277

217. Plitas G, Konopacki C, Wu K, Bos PD, Morrow M, Putintseva EV, et al. Regulatory T cells exhibit distinct features in human breast cancer. Immunity (2016) 45(5):1122-34. doi:10.1016/j.immuni.2016.10.032 
218. Leonard JD, Gilmore DC, Dileepan T, Nawrocka WI, Chao JL, Schoenbach MH, et al. Identification of natural regulatory $\mathrm{T}$ cell epitopes reveals convergence on a dominant autoantigen. Immunity (2017) 47(1):107-17.e8. doi:10.1016/j.immuni.2017.06.015

219. Waight JD, Takai S, Marelli B, Qin G, Hance KW, Zhang D, et al. Cutting edge: epigenetic regulation of Foxp3 defines a stable population of CD4+ regulatory $\mathrm{T}$ cells in tumors from mice and humans. JImmunol (2015) 194(3):878-82. doi:10.4049/jimmunol.1402725

220. Polansky JK, Kretschmer K, Freyer J, Floess S, Garbe A, Baron U, et al. DNA methylation controls Foxp3 gene expression. Eur J Immunol (2008) 38(6):1654-63. doi:10.1002/eji.200838105

221. Ohkura N, Hamaguchi M, Morikawa H, Sugimura K, Tanaka A, Ito Y, et al. $\mathrm{T}$ cell receptor stimulation-induced epigenetic changes and Foxp3 expression are independent and complementary events required for Treg cell development. Immunity (2012) 37(5):785-99. doi:10.1016/j.immuni.2012. 09.010

222. De Simone M, Arrigoni A, Rossetti G, Gruarin P, Ranzani V, Politano C, et al. Transcriptional landscape of human tissue lymphocytes unveils uniqueness of tumor-infiltrating T regulatory cells. Immunity (2016) 45(5): 1135-47. doi:10.1016/j.immuni.2016.10.021

223. Sobecki M, Mrouj K, Camasses A, Parisis N, Nicolas E, Lleres D, et al. The cell proliferation antigen Ki-67 organises heterochromatin. Elife (2016) 5:e13722. doi:10.7554/eLife.13722

224. Hayatsu N, Miyao T, Tachibana M, Murakami R, Kimura A, Kato T, et al. Analyses of a mutant Foxp3 allele reveal BATF as a critical transcription factor in the differentiation and accumulation of tissue regulatory $\mathrm{T}$ cells. Immunity (2017) 47(2):268-83.e9. doi:10.1016/j.immuni.2017.07.008

225. Soler D, Chapman TR, Poisson LR, Wang L, Cote-Sierra J, Ryan M, et al. CCR8 expression identifies CD4 memory T cells enriched for FOXP3+ regulatory and Th2 effector lymphocytes. J Immunol (2006) 177(10):6940-51. doi:10.4049/jimmunol.177.10.6940

226. Islam SA, Chang DS, Colvin RA, Byrne MH, McCully ML, Moser B, et al. Mouse CCL8, a CCR8 agonist, promotes atopic dermatitis by recruiting IL-5+ T(H)2 cells. Nat Immunol (2011) 12(2):167-77. doi:10.1038/ ni. 1984

227. Nakayama T, Kato Y, Hieshima K, Nagakubo D, Kunori Y, Fujisawa T, et al. Liver-expressed chemokine/CC chemokine ligand 16 attracts eosinophils by interacting with histamine H4 receptor. J Immunol (2004) 173(3): 2078-83. doi:10.4049/jimmunol.173.3.2078

228. Islam SA, Ling MF, Leung J, Shreffler WG, Luster AD. Identification of human CCR8 as a CCL18 receptor. J Exp Med (2013) 210(10):1889-98. doi:10.1084/ jem. 20130240

229. Xie Q, Klesney-Tait J, Keck K, Parlet C, Borcherding N, Kolb R, et al. Characterization of a novel mouse model with genetic deletion of CD177. Protein Cell (2015) 6(2):117-26. doi:10.1007/s13238-014-0109-1

230. Murata M, Yudoh K, Shimizu H, Beppu M, Nakamura H, Kato T, et al. Layilin, a talin-binding hyaluronan receptor, is expressed in human articular chondrocytes and synoviocytes and is down-regulated by interleukin1beta. Mod Rheumatol (2013) 23(3):478-88. doi:10.3109/s10165-012-0686-x

231. Kurose K, Ohue $\mathrm{Y}$, Wada H, Iida S, Ishida T, Kojima T, et al. Phase Ia study of FoxP3+ CD4 Treg depletion by infusion of a humanized anti-CCR4 antibody, KW-0761, in cancer patients. Clin Cancer Res (2015) 21(19):4327-36. doi:10.1158/1078-0432.CCR-15-0357

232. Barsheshet Y, Wildbaum G, Levy E, Vitenshtein A, Akinseye C, Griggs J, et al. CCR8(+)FOXp3(+) Treg cells as master drivers of immune regulation. Proc Natl Acad Sci U S A (2017) 114(23):6086-91. doi:10.1073/pnas. 1621280114

233. Liu C, Workman CJ, Vignali DA. Targeting regulatory T cells in tumors. FEBS J (2016) 283(14):2731-48. doi:10.1111/febs.13656

234. Campbell DJ, Koch MA. Phenotypical and functional specialization of FOXP3+ regulatory T cells. Nat Rev Immunol (2011) 11(2):119-30. doi:10.1038/ nri2916

235. Chinen T, Kannan AK, Levine AG, Fan X, Klein U, Zheng Y, et al. An essential role for the IL-2 receptor in Treg cell function. Nat Immunol (2016) 17(11):1322-33. doi:10.1038/ni.3540

236. Cao X, Cai SF, Fehniger TA, Song J, Collins LI, Piwnica-Worms DR, et al. Granzyme B and perforin are important for regulatory $\mathrm{T}$ cell-mediated suppression of tumor clearance. Immunity (2007) 27(4):635-46. doi:10.1016/j. immuni.2007.08.014
237. Wing K, Onishi Y, Prieto-Martin P, Yamaguchi T, Miyara M, Fehervari Z, et al. CTLA-4 control over Foxp3+ regulatory T cell function. Science (2008) 322(5899):271-5. doi:10.1126/science.1160062

238. Sharma MD, Shinde R, McGaha TL, Huang L, Holmgaard RB, Wolchok JD, et al. The PTEN pathway in Tregs is a critical driver of the suppressive tumor microenvironment. Sci Adv (2015) 1(10):e1500845. doi:10.1126/sciadv. 1500845

239. Jacobs JF, Idema AJ, Bol KF, Nierkens S, Grauer OM, Wesseling P, et al. Regulatory $\mathrm{T}$ cells and the PD-L1/PD-1 pathway mediate immune suppression in malignant human brain tumors. Neuro Oncol (2009) 11(4):394-402. doi:10.1215/15228517-2008-104

240. Liang B, Workman C, Lee J, Chew C, Dale BM, Colonna L, et al. Regulatory $\mathrm{T}$ cells inhibit dendritic cells by lymphocyte activation gene- 3 engagement of MHC class II. J Immunol (2008) 180(9):5916-26. doi:10.4049/jimmunol. 180.9.5916

241. Gautron AS, Dominguez-Villar M, de Marcken M, Hafler DA. Enhanced suppressor function of TIM-3+ FoxP3+ regulatory T cells. Eur J Immunol (2014) 44(9):2703-11. doi:10.1002/eji.201344392

242. Stagg J, Divisekera U, Duret H, Sparwasser T, Teng MW, Darcy PK, et al. CD73-deficient mice have increased antitumor immunity and are resistant to experimental metastasis. Cancer Res (2011) 71(8):2892-900. doi:10.1158/0008-5472.CAN-10-4246

243. Borsellino G, Kleinewietfeld M, Di Mitri D, Sternjak A, Diamantini A, Giometto R, et al. Expression of ectonucleotidase CD39 by Foxp3+ Treg cells: hydrolysis of extracellular ATP and immune suppression. Blood (2007) 110(4):1225-32. doi:10.1182/blood-2006-12-064527

244. Maj T, Wang W, Crespo J, Zhang H, Wang W, Wei S, et al. Oxidative stress controls regulatory $\mathrm{T}$ cell apoptosis and suppressor activity and PD-L1-blockade resistance in tumor. Nat Immunol (2017) 18(12):1332-41. doi: $10.1038 /$ ni.3868

245. Li N, Alam J, Venkatesan MI, Eiguren-Fernandez A, Schmitz D, Di Stefano E, et al. Nrf2 is a key transcription factor that regulates antioxidant defense in macrophages and epithelial cells: protecting against the proinflammatory and oxidizing effects of diesel exhaust chemicals. J Immunol (2004) 173(5):3467-81. doi:10.4049/jimmunol.173.5.3467

246. Balachandran VP, Cavnar MJ, Zeng S, Bamboat ZM, Ocuin LM, Obaid H, et al. Imatinib potentiates antitumor $\mathrm{T}$ cell responses in gastrointestinal stromal tumor through the inhibition of Ido. Nat Med (2011) 17(9):1094-100. doi: $10.1038 / \mathrm{nm} .2438$

247. Delgoffe GM, Woo SR, Turnis ME, Gravano DM, Guy C, Overacre AE, et al. Stability and function of regulatory $\mathrm{T}$ cells is maintained by a neuropilin-1-semaphorin-4a axis. Nature (2013) 501(7466):252-6. doi:10.1038/nature 12428

248. Noman MZ, Hasmim M, Messai Y, Terry S, Kieda C, Janji B, et al. Hypoxia: a key player in antitumor immune response. A review in the theme: cellular responses to hypoxia. Am J Physiol Cell Physiol (2015) 309(9):C569-79. doi:10.1152/ajpcell.00207.2015

249. Wilson WR, Hay MP. Targeting hypoxia in cancer therapy. Nat Rev Cancer (2011) 11(6):393-410. doi:10.1038/nrc3064

250. Tan W, Zhang W, Strasner A, Grivennikov S, Cheng JQ, Hoffman RM, et al. Tumour-infiltrating regulatory $\mathrm{T}$ cells stimulate mammary cancer metastasis through RANKL-RANK signalling. Nature (2011) 470(7335):548-53. doi:10.1038/nature09707

251. Cao Y, Luo JL, Karin M. IkappaB kinase alpha kinase activity is required for self-renewal of ErbB2/Her2-transformed mammary tumor-initiating cells. Proc Natl Acad Sci U S A (2007) 104(40):15852-7. doi:10.1073/ pnas. 0706728104

252. Luo JL, Tan W, Ricono JM, Korchynskyi O, Zhang M, Gonias SL, et al. Nuclear cytokine-activated IKK alpha controls prostate cancer metastasis by repressing Maspin. Nature (2007) 446(7136):690-4. doi:10.1038/ nature 05656

253. Mock JR, Garibaldi BT, Aggarwal NR, Jenkins J, Limjunyawong N, Singer BD, et al. Foxp3+ regulatory T cells promote lung epithelial proliferation. Mucosal Immunol (2014) 7(6):1440-51. doi:10.1038/mi.2014.33

254. Le G, Lowe DA, Kyba M. Freeze injury of the tibialis anterior muscle. Methods Mol Biol (2016) 1460:33-41. doi:10.1007/978-1-4939-3810-0_3

255. Warren GL, Hulderman T, Mishra D, Gao X, Millecchia L, O'Farrell L, et al. Chemokine receptor CCR2 involvement in skeletal muscle regeneration. FASEB J (2005) 19(3):413-5. doi:10.1096/f.04-2421fje 
256. Chu M, Gregorio CC, Pappas CT. Nebulin, a multi-functional giant. J Exp Biol (2016) 219(Pt 2):146-52. doi:10.1242/jeb.126383

257. Kuswanto W, Burzyn D, Panduro M, Wang KK, Jang YC, Wagers AJ, et al. Poor repair of skeletal muscle in aging mice reflects a defect in local, interleukin-33-dependent accumulation of regulatory T cells. Immunity (2016) 44(2):355-67. doi:10.1016/j.immuni.2016.01.009

258. Hui SP, Sheng DZ, Sugimoto K, Gonzalez-Rajal A, Nakagawa S, Hesselson D, et al. Zebrafish regulatory $\mathrm{T}$ cells mediate organ-specific regenerative programs. Dev Cell (2017) 43(6):659-72.e5. doi:10.1016/j.devcel.2017.11.010

259. Samstein RM, Josefowicz SZ, Arvey A, Treuting PM, Rudensky AY. Extrathymic generation of regulatory $\mathrm{T}$ cells in placental mammals mitigates maternalfetal conflict. Cell (2012) 150(1):29-38. doi:10.1016/j.cell.2012.05.031

260. Robertson SA, Prins JR, Sharkey DJ, Moldenhauer LM. Seminal fluid and the generation of regulatory T cells for embryo implantation. Am J Reprod Immunol (2013) 69(4):315-30. doi:10.1111/aji.12107

261. Ruocco MG, Chaouat G, Florez L, Bensussan A, Klatzmann D. Regulatory T-cells in pregnancy: historical perspective, state of the art, and burning questions. Front Immunol (2014) 5:389. doi:10.3389/fimmu.2014.00389

262. Arruvito L, Sanz M, Banham AH, Fainboim L. Expansion of CD4+CD25+and FOXP3+ regulatory $\mathrm{T}$ cells during the follicular phase of the menstrual cycle: implications for human reproduction. J Immunol (2007) 178(4):2572-8. doi:10.4049/jimmunol.178.4.2572

263. McGovern N, Shin A, Low G, Low D, Duan K, Yao LJ, et al. Human fetal dendritic cells promote prenatal T-cell immune suppression through arginase-2. Nature (2017) 546(7660):662-6. doi:10.1038/nature22795

264. Mold JE, Michaelsson J, Burt TD, Muench MO, Beckerman KP, Busch MP, et al. Maternal alloantigens promote the development of tolerogenic fetal regulatory T cells in utero. Science (2008) 322(5907):1562-5. doi:10.1126/ science. 1164511

265. Allenspach EJ, Finn LS, Rendi MH, Eken A, Singh AK, Oukka M, et al. Absence of functional fetal regulatory $\mathrm{T}$ cells in humans causes in utero organ-specific autoimmunity. J Allergy Clin Immunol (2017) 140(2):616-9. e7. doi:10.1016/j.jaci.2017.02.017

266. Tung KS, Harakal J, Qiao H, Rival C, Li JC, Paul AG, et al. Egress of sperm autoantigen from seminiferous tubules maintains systemic tolerance. J Clin Invest (2017) 127(3):1046-60. doi:10.1172/JCI89927
267. Deliyanti D, Talia DM, Zhu T, Maxwell MJ, Agrotis A, Jerome JR, et al. Foxp3(+) Tregs are recruited to the retina to repair pathological angiogenesis. Nat Commun (2017) 8(1):748. doi:10.1038/s41467-017-00751-w

268. Naldaiz-Gastesi N, Goicoechea M, Alonso-Martin S, Aiastui A, LopezMayorga M, Garcia-Belda P, et al. Identification and characterization of the dermal panniculus carnosus muscle stem cells. Stem Cell Reports (2016) 7(3):411-24. doi:10.1016/j.stemcr.2016.08.002

269. MacDonald KG, Hoeppli RE, Huang Q, Gillies J, Luciani DS, Orban PC, et al. Alloantigen-specific regulatory $\mathrm{T}$ cells generated with a chimeric antigen receptor. J Clin Invest (2016) 126(4):1413-24. doi:10.1172/JCI82771

270. Angelin A, Gil-de-Gomez L, Dahiya S, Jiao J, Guo L, Levine MH, et al. Foxp3 reprograms $\mathrm{T}$ cell metabolism to function in low-glucose, highlactate environments. Cell Metab (2017) 25:1282-93.e7. doi:10.1016/j. cmet.2016.12.018

271. Gerriets VA, Kishton RJ, Johnson MO, Cohen S, Siska PJ, Nichols AG, et al. Foxp3 and toll-like receptor signaling balance Treg cell anabolic metabolism for suppression. Nat Immunol (2016) 17:1459-66. doi:10.1038/ ni. 3577

272. Ho PC, Bihuniak JD, Macintyre AN, Staron M, Liu X, Amezquita R, et al. Phosphoenolpyruvate is a metabolic checkpoint of anti-tumor $\mathrm{T}$ cell responses. Cell (2015) 162(6):1217-28. doi:10.1016/j.cell.2015.08.012

273. Kishore M, Cheung KCP, Fu H, Bonacina F, Wang G, Coe D, et al. Regulatory $\mathrm{T}$ cell migration is dependent on glucokinase-mediated glycolysis. Immunity (2017) 47(5):875-89.e10. doi:10.1016/j.immuni.2017.10.017

Conflict of Interest Statement: The authors declare that the research was conducted in the absence of any commercial or financial relationships that could be construed as a potential conflict of interest.

Copyright $\odot 2018$ Sharma and Rudra. This is an open-access article distributed under the terms of the Creative Commons Attribution License (CC BY). The use, distribution or reproduction in other forums is permitted, provided the original author(s) and the copyright owner are credited and that the original publication in this journal is cited, in accordance with accepted academic practice. No use, distribution or reproduction is permitted which does not comply with these terms. 